\title{
A New Synuclein-Transgenic Mouse Model for Early Parkinson's Reveals Molecular Features of Preclinical Disease
}

\author{
Diana M. Hendrickx ${ }^{1}$ (D) . Pierre Garcia ${ }^{1,2}$. Amer Ashrafi, ${ }^{1,3}$. Alessia Sciortino ${ }^{1}$ - Kristopher J. Schmit ${ }^{1}$.

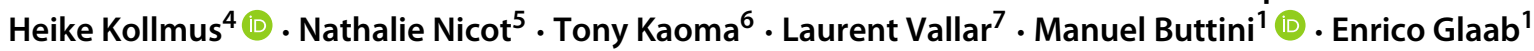

Received: 8 April 2020 / Accepted: 21 August 2020

(C) The Author(s) 2020

\begin{abstract}
Understanding Parkinson's disease (PD), in particular in its earliest phases, is important for diagnosis and treatment. However, human brain samples are collected post-mortem, reflecting mainly end-stage disease. Because brain samples of mouse models can be collected at any stage of the disease process, they are useful in investigating PD progression. Here, we compare ventral midbrain transcriptomics profiles from $\alpha$-synuclein transgenic mice with a progressive, early PD-like striatal neurodegeneration across different ages using pathway, gene set, and network analysis methods. Our study uncovers statistically significant altered genes across ages and between genotypes with known, suspected, or unknown function in PD pathogenesis and key pathways associated with disease progression. Among those are genotype-dependent alterations associated with synaptic plasticity and neurotransmission, as well as mitochondria-related genes and dysregulation of lipid metabolism. Age-dependent changes were among others observed in neuronal and synaptic activity, calcium homeostasis, and membrane receptor signaling pathways, many of which linked to G-protein coupled receptors. Most importantly, most changes occurred before neurodegeneration was detected in this model, which points to a sequence of gene expression events that may be relevant for disease initiation and progression. It is tempting to speculate that molecular changes similar to those changes observed in our model happen in midbrain dopaminergic neurons before they start to degenerate. In other words, we believe we have uncovered molecular changes that accompany the progression from preclinical to early PD.
\end{abstract}

Keywords Parkinson's disease · Transgenic mouse model $\cdot \alpha$-Synuclein $\cdot$ Disease-stage $\cdot$ Pathway analysis Network analysis

\section{Introduction}

The current understanding of the molecular mechanisms behind initiation and progression of Parkinson's disease (PD) is still limited. Previous molecular studies on human

Diana M Hendrickx and Pierre Garcia contributed equally to this work.

Manuel Buttini and Enrico Glaab contributed equally to this work.

Electronic Supplementary Material The online version of this article (https://doi.org/10.1007/s12035-020-02085-z) contains supplementary material, which is available to authorized users.

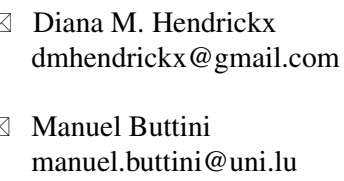

Extended author information available on the last page of the article. post-mortem brain tissues mostly stem from late stages of PD [44, 75], making it difficult to infer causality between molecular events and pathological outcome. In addition, long post-mortem delays, several comorbidities, and high inter-individual variations complicate the interpretation of molecular data. By contrast, samples from PD mouse models can be collected at any stage of the disease process, and a shared genetic background reduces inter-individual variations. Therefore, mouse models provide a useful means to investigate PD-associated molecular changes, in particular those preceding nigro-striatal degeneration. The elucidation of such early changes can shed light into disease causation and drivers of disease progression, thus in turn pointing to novel targets for intervention as well as biomarkers [22, 58].

Whole transcriptome analysis enables comparison of thousands of genes between two or more groups [11], and provides a valuable method for identifying coordinated changes in gene expression patterns that are not captured 
by single-gene or protein measurement approaches [72]. Despite these advantages, only a limited amount of studies have used transcriptomics on $\alpha$-synuclein-based transgenic mouse models for PD [16, 81, 87-89, 120, 124]. Alphasynuclein, a pre-synaptic protein believed to be a moderator of the synaptic vesicle cycle, is a major component of Lewy bodies [108]. In addition, mutations or multiplications in its genes leads to familiar forms of PD [34, 59]. Transcriptomics studies on $\alpha$-synuclein-based transgenic mouse models for PD have only looked at differentially expressed genes (DEGs) in relation to pre-defined cellular pathways or gene sets from public annotation databases $[16,81,87-89,120]$. Most of them used only one [87-89] or two age groups $[16,81,120,124]$ of a mouse model for their analyses, and some of them were performed in brain regions not containing dopaminergic neurons [16, 87]. Furthermore, these studies did not build custom networks from the output of the differential expression analysis by mapping each list of DEGs to a genome-scale proteinprotein interaction network. An advantage of this approach is that more molecular interactions are covered than in public pathway or gene set databases. They also did not perform text mining analyses to identify putative cooccurrence associations between the human orthologues of the DEGs and Parkinson's disease (PD) described in the literature. Finally, previous studies lack an analysis of how their findings can be translated from mouse to human biology, by systematically comparing DEGs with their human orthologues, and comparing the cellular sources of DEGs (main brain cell type where the DEGs are expressed) between mice and humans.

In this study, we characterized a new genomic $\alpha$ synuclein transgenic model, the BAC-Tg3(SNCA*E46K) "Line 3" mice, and performed transcriptomic profiling of the ventral midbrain at 3 different ages. We found that a key factor of this model is age-dependent degeneration in the dorsal striatum, the main projection area of substantia nigra (SN) dopaminergic neurons [106, 131], without these neurons being lost, a phenotype reminiscent of prodromal and early PD [63]. We were interested in molecular changes driven by the $\alpha$-synuclein transgene in the ventral midbrain at each age and across ages, and wanted to assess their disease relevance. To do this, we first identified the human orthologues of all DEGs, then applied bioinformatical analyses consisting of (i) text mining, (ii) cellular pathway identification, and (iii) molecular sub-network analysis, both for within- and between-age comparisons. Additionally, (iv) the cellular source of the DEGs across different brain cell types was determined for both mouse and human in order to identify similarities and differences between these two species in a PD context. Our study shows that, in this model, disease-related molecular changes at the gene expression level occur quite early, and evolve over time well before striatal degeneration reaches its peak. Our results indicate that the BAC-Tg3(SNCA*E46K) mouse line changes may provide a window into the earliest phases of PD pathology.

\section{Materials and Methods}

\section{Phenotyping and Tissue Preparation}

\section{Mouse Cohorts}

In this study, female mice were used at 3,9, and 13 months of age $(3 \mathrm{M}, 9 \mathrm{M}, 13 \mathrm{M})$. Each age group was composed of 8 heterozygote SNCA transgene carriers (HET) and 8 wild-type (WT) littermate controls. A total of 48 female mice were used in this study. Future studies will look also at males and at other PD-related genes. It is also important to note that some ethnicities do not show higher incidence and prevalence in males than in females (see "Discussion"). The transgenic mouse line BAC-Tg3(SNCA*E46K), also called $\operatorname{Tg}\left(\mathrm{SNCA}^{*} \mathrm{E} 46 \mathrm{~K}\right) 3 \mathrm{Elan} / \mathrm{J}$ or "Line 3" was originally generated by Elan Pharmaceuticals, USA, as described in detail in [38]. Briefly, the E46K mutation [130] was introduced using the Bacterial Artificial Chromosome (BAC) as described in [70]. The E46K mutation was chosen because in cultured neurons it is more toxic than the $\mathrm{A} 30 \mathrm{P}$ and A53T mutations [52]. The mutation was confirmed by sequencing the circular BAC constructs containing the hSNCA transgene $(\sim 168 \mathrm{~Kb})$, which were used to perform pronuclear microinjection. Founders were identified by PCR genotyping using designated PCR primers described in [38]. Then, mice were bred for over 10 generations with B6D2F1 mice (Jackson laboratories) and maintained as heterozygotes on this background, and non-TG littermates served as controls in study cohorts. For this study, mice were bred in the animal facility at the Helmholtz Institute Braunschweig under specific pathogen-free (SPF), climate controlled, and given food and water ad libitum.

Genotyping by PCR (primer pair $5^{\prime}-3^{\prime}$ : forward GAT-TTCCTT-CTT-TGT-CTC-CTA-TAG-CAC-TGG, reverse GAAGCA-GGT-ATT-ACT-GGC-AGA-TGA-GGC) was performed on tail biopsies following the instructions found on http://www.informatics.jax.org/external/ko/deltagen/462_

MolBio.html. A genotyping kit (Kapabiosystems, KR0385v2.13) was used, following manufacturer's instructions. Briefly, a mixture of $12.5 \mu \mathrm{l}$ of "2xKAPA2G Fast Hot Start Genotyping Mix" (DNA polymerase containing mix provided with the kit mentioned in the previous section), 1 $\mu \mathrm{l}$ of template DNA previously prepared, $1.25 \mu \mathrm{l}$ of $10 \mu \mathrm{M}$ forward primer, and $1.25 \mu \mathrm{l}$ of $10 \mu \mathrm{M}$ reverse primer was prepared in a PCR tube in a total volume reaction of $25 \mu \mathrm{l}$. The PCR products were loaded onto a $1.5 \%$ agarose gel for 
separation by electrophoresis, and viewed under UV after Ethidium bromide incubation.

\section{Mouse Brain Tissue Preparation and RNA Extraction}

All mice were euthanized in a deep anesthesia (i.p. injection of $10 \mathrm{mg} / \mathrm{kg}$ xylazin and ketamine, $100 \mathrm{mg} / \mathrm{kg}$ ) by transcardial transfusion with PBS. After removal from the skull, brains were dissected on ice into regions, and ventral midbrains (the region enriched in dopaminergic neurons) were snap-frozen on dry ice and stored at $-80^{\circ} \mathrm{C}$ until further processing. For RNA extraction, the RNeasy Universal Kit (Qiagen) was used, after homogenization of midbrain tissues in a Retsch MM 400 device ( 2 min at $22 \mathrm{~Hz}$, Haan, Germany). RNA concentrations and integrity were determined using a Nanodrop 2000c (Thermo Scientific) and a BioAnalyzer 2100 (Agilent), respectively. Purified RNAs were considered of sufficient quality if their RNA integrity value was above 8.5 , their $260 / 230$ absorbance ratio $=1.8$, and their $260 / 280$ absorbance ratio $=2$. RNA samples were stored at $-80^{\circ} \mathrm{C}$ until further use.

\section{Transgene Expression Levels by RT-PCR}

Real-Time RT-qPCR Complementary DNA (cDNA) was prepared from $1 \mu \mathrm{g}$ of total RNA, using SuperScript III reverse transcriptase (Invitrogen). A mix of RNA, oligo $\mathrm{dT}_{20} 50 \mu \mathrm{M}, 10 \mathrm{mM}$ dNTPs, and sterile distilled water up to $13 \mu \mathrm{l}$ was heated at $65^{\circ} \mathrm{C}$ for $5 \mathrm{~min}$, and chilled on ice for at least 1 min prior to the addition of a mixture of $5 \mathrm{X}$ FirstStrand Buffer, 0.1 M DTT, Rnase OUT, and SuperScript ${ }^{\mathrm{TM}}$ III RT (200 units/ $\mu$ l). The complete reaction was incubated at $50{ }^{\circ} \mathrm{C}$ for $60 \mathrm{~min}$, followed by SuperScript inactivation at $70{ }^{\circ} \mathrm{C}$ for $15 \mathrm{~min}$. Reaction tubes without Reverse Transcriptase and containing PCR water instead of RNA were included as negative controls. A total of $80 \mu \mathrm{l}$ of Rnase-free water was added to the reaction, and the cDNA was placed on ice for immediate use or stored at $-20{ }^{\circ} \mathrm{C}$ for future use. Real-time RT-qPCR assays were performed using primers specific for human SNCA (forward 5'- AAG-AGGGTG-TTC-TCT-ATG-TAG-GC-3'; reverse 5'- GCT-CCTCCA-ACA-TTT-GTC-ACT-T- $3^{\prime}$ ), murine Snca (forward $5^{\prime}$ - CGC-ACC-TCC-AAC-CAA-CCC-G-3'; reverse $5^{\prime}$ TGA-TTT-GTC-AGC-GCC-TCT-CCC- $3^{\prime}$ ), or total synuclein (forward 5'- GAT-CCT-GGC-AGT-GAG-GCT-TA-3'; reverse $5^{\prime}$ - GCT-TCA-GGC-TCA-TAG-TCT-TGG-3'), with GAPDH (forward 5'- TGC-GAC-TTC-AAC-AGC-AACTC-3'; reverse $5^{\prime}$-CTT-GCT-CAG-TGT-CCT-TGC-TG-3') as an internal housekeeping transcript. The qPCR reaction contained $2 \mu \mathrm{l}$ of cDNA, $10 \mu \mathrm{M}$ forward and reverse primers, $1 \mathrm{X} \mathrm{iQ}^{T M} \mathrm{SYBR}{ }^{\circledR}$ Green Supermix (Bio-Rad), and PCR-grade water up to a volume of $20 \mu \mathrm{l}$. Each qPCR reaction was run in triplicate on a LightCycler®480 II (Roche).
The thermocycling profile included an initial denaturation of $3 \mathrm{~min}$ at $95^{\circ} \mathrm{C}$, followed by 40 cycles of $95^{\circ} \mathrm{C}$ for $30 \mathrm{~s}$, $62{ }^{\circ} \mathrm{C}$ for $30 \mathrm{~s}$, and $72{ }^{\circ} \mathrm{C}$ for $30 \mathrm{~s}$ with fluorescent data collection during the $62{ }^{\circ} \mathrm{C}$ step. Data acquisition was performed by LightCycler®480 Software release 1.5.0 SP4, version 1.5.0.39. Expression values for each target gene were normalized to the housekeeping gene GAPDH $(\Delta C t)$, and the results are shown as fold change in expression $\left(2^{-\Delta C t}\right)$.

\section{Immunostaining Procedure}

Immunofluorescence was performed using standard procedures. Fifty-micron free-floating sections were washed (2 x 5 min) under circular agitation in washing buffer (PBS with $0.1 \%$ Triton $\mathrm{X}-100$ ), then permeabilized for $30 \mathrm{~min}$ in PBS containing $1.5 \%$ Triton X-100 and 3\% hydrogen peroxide (Sigma; \#31642). Then, sections were washed again in washing buffer ( $2 \times 5 \mathrm{~min})$ before being incubated in the same buffer with $5 \%$ bovine serum albumin (BSA, Sigma, A7030) as blocking solution for $30 \mathrm{~min}$. After being rinsed ( $2 \times 5 \mathrm{~min})$, sections were incubated with primary antibodies (mouse anti-human synuclein, Sigma S5566 (clone SYN211) for human alpha-synuclein; rabbit anti-synuclein, Sigma S3062, for both human and mouse alpha-synuclein) diluted 1:1000 in washing buffer supplemented with $0.3 \%$ Triton X-100, $2 \%$ BSA, overnight with shaking at room temperature. After 3 more washing steps (10 min each), sections were incubated with appropriate secondary antibodies (goat anti-rabbit coupled to Alexa-488, Invitrogen A11034; or goat anti-mouse coupled to Alexa-488, Invitrogen A21121), diluted 1:1000 in washing buffer, in the dark for $2 \mathrm{~h}$ at room temperature. Next, the sections were washed ( $3 \times 10 \mathrm{~min}$ ) in washing buffer, and once in TBS (Trizma base $6.06 \mathrm{~g} \mathrm{~L}^{-1}, 8.77 \mathrm{~g} \mathrm{~L}^{-1} \mathrm{NaCl}$, adjusted with $\mathrm{HCl}$ to $\mathrm{pH}$ 7.4). Finally, sections were mounted on glass slides, coverslipped using Dako fluorescent mounting medium (DAKO NA; \#S3023), and imaged, at least $24 \mathrm{~h}$ later, using a Zeiss LabA1 microscope, coupled to a Zeiss Axiocam MRm3 digital camera, and to a PC using the Zeiss Zen Blue 2012 software.

\section{Quantitation of Nigro-Striatal Degeneration}

Immunofluorescence staining for tyrosine hydroxylase (TH) and dopamine transporter (DAT) was performed using standard procedures as described above. Sections were double-stained for both markers. Primary antibodies (chicken anti-TH, Abcam \#76442; Rat anti DAT, Millipore MAB369) were diluted 1:1000 in washing buffer containing $0.3 \%$ Triton X-100, 2\% BSA, and incubated with sections overnight, with shaking, at room temperature. Secondary antibodies (goat anti-chicken coupled to Alexa 488; goat 
anti-rat coupled to Alexa 594 Invitrogen A11007), diluted 1:1000 in washing buffer, were incubated with sections in the dark for $2 \mathrm{~h}$ at room temperature. Then, sections were mounted on Superfrost glass slides, coverslipped using Dako fluorescent mounting medium (DAKO; \#S3023), and imaged at least $24 \mathrm{~h}$ later. Imaging was done using a Zeiss AxioImager Z1 upright microscope equipped with a PRIOR motorized slide stage, coupled to a "Colibri" LED system to generate fluorescence light of defined wavelengths, and an Mrm3 digital camera for image capture. Striatal pictures were acquired using the apotome module at $\times 40$ magnification (picture size: $223 \times 167 \mu \mathrm{m}$ ), and SN was acquired at $\times 10$ magnification (picture size: $895 \times 670 \mu \mathrm{m})$ with regular epifluorescence. The Zeiss imaging system was controlled by Zeiss' Blue Vision software. Because $\mathrm{TH}$ and DAT detections on sections were performed as a double staining, we tested for the absence of fluorescent bleed-through between the secondary antibodies used for that staining. Sections singly stained for $\mathrm{TH}$, which was revealed with an Alexa-488 coupled secondary antibody, were first viewed with the appropriate filters, then with the filters used for viewing Alexa-594. Conversely, sections singly stained for DAT, which was revealed with an Alexa-594 coupled secondary antibody, were first viewed with the appropriate filters, then with a filter used for Alexa-488. In both cases when the sections were viewed with inappropriate filters, no signal was visible (Fig. S1), thus showing the absence of bleedthrough. To determine neurodegeneration in the striatum [77], 2-3 striatal sections per animal were imaged, and 3 pictures from the dorsal striatum were collected for each section. Images were converted to TIFF format. Then, after thresholding, the percent format area occupied by TH- or DAT-positive structures was measured using the publicly available imaging software FIJI [101]. Measuring of relative levels of human $\alpha$-syn and its correlation with loss of TH-positive axons in the striatum was done on $\mathrm{TH} / \alpha$-syn double-labeled sections. For all images used for quantitation of $\mathrm{TH}$, a parallel quantitation of $\alpha$-syn was performed. Since the images were 8-bit images, the relative level of $\alpha$-syn was measured, using the same imaging software, by determining the mean gray value, on a scale of $0-255$, of $\alpha$-syn-positive synapses, similar to the approach described in [15]. Degeneration of SNs was assessed as described in the supplementary material in Ashrafi et al. [5]. Briefly, $895 \times 670 \mu \mathrm{m}$ pictures of the whole SNs were sampled each 4th section throughout the whole ventral midbrain, and each picture was assigned to one of the four SN typical subregions. The selected four pictures from the four subregions from each mouse were summed together to calculate the
"Cumulated surface" used for the quantification. This method has been validated by stereological assessment of the total number of TH-positive neurons in the SN. All individual values for the different measurements obtained for each mouse were averaged to give one value for each mouse. All quantitation measurements were performed on blinded sections and codes were not broken until the measurements were completed.

Statistical analyses were done using the GraphPad Prism version 8.0.0 for Windows, GraphPad Software, San Diego, CA, USA. Normality of data distribution was tested with Kolmogorov-Smirnov normality test. All datasets analyzed showed a normal distribution, thus two-way ANOVA (for two independent variables, in this case genotype and age), followed by Tukey's or Sidak's test post hoc, was used. Significance of correlation was tested by Pearson's test. A $p$ value below 0.05 was considered significant for all analyses.

\section{Microarray Analysis}

RNA purity and integrity were re-confirmed NanoDrop 1ND-1000 spectrophotometer and Agilent 2100 Bioanalyzer with RNA 6000 Nano assay kit. Only RNAs with no sign of marked degradation ( RIN > 7-8) were considered good quality and used for further analysis. GeneChip Mouse Gene 2.0ST Arrays (Affymetrix) were used. Total RNAs $(150 \mathrm{ng})$ were processed using the Affymetrix GeneChip ${ }^{\circledR}$ WT PLUS Reagent Kit according to the manufacturer's instructions (Manual Target Preparation for GeneChip ${ }^{\circledR}$ Whole Transcript (WT) Expression Arrays P/N 703174 Rev. $2)$. In this procedure, adapted from [13], the purified, sensestrand cDNA is fragmented by uracil-DNA glycosylase (UDG) and apurinic/apyrimidinic endonuclease 1 (APE 1) at the unnatural dUTP residues and breaks the DNA strand. The fragmented cDNA was labelled by terminal deoxynucleotidyl transferase (TdT) using the Affymetrix proprietary DNA Labelling Reagent that is covalently linked to biotin; $5.5 \mu \mathrm{g}$ of single-stranded cDNA are required for fragmentation and labelling, then $3.5 \mu \mathrm{g}$ of labeled DNA and hybridization controls was injected into an Affymetrix cartridge. Microarrays were then incubated in the Affymetrix Oven with rotation at $60 \mathrm{rpm}$ for $16 \mathrm{~h}$ at $45^{\circ} \mathrm{C}$, then the arrays were washed and scanned with the Affymetrix ${ }^{\circledR}$ GeneChip ${ }^{\circledR}$ Scanner 3000, based on the following protocol: UserGuide GeneChip ${ }^{\circledR}$ Expression Wash, Stain and Scan for Cartridge Arrays P/N 702731 Rev. 4, which generated the Affymetrix raw data CEL files containing hybridization raw signal intensities. All microarray analyses were conducted in the same run as one batch. 


\section{Pre-Processing and Quality Control}

Probe correction, removal of array-specific background noise, and normalization were performed using the SCAN preprocessing procedure [90], implemented in the Bioconductor [39, 51] SCAN.UPC package (version 2.24.1).

The Bioconductor arrayQualityMetrics package (version 3.38.0) was used for quality control. Samples were removed if at least two of the three following quality control tests failed: outlier test of distances between arrays, boxplots, MA plots (i.e., the scatter plots of the distribution of the $\log 2$ expression ratio (M) against the average expression signal (A)) [60].

\section{Bioinformatics Tools and Statistical Analyses}

\section{An Overview}

The workflow for our analyses is depicted in Fig. 1. After pre-processing and quality control, differentially expressed genes (DEGs) between genotypes for each age group (HET versus WT; genotype-dependent DEGs), as well as DEGs between age groups for each genotype separately (3M versus $9 \mathrm{M}, 9 \mathrm{M}$ versus $13 \mathrm{M}$; age-dependent $\mathrm{DEGs}$ ) were determined. We used the resulting lists of DEGs for text mining, molecular pathway, gene set, and network analyses. We also determined the cellular origin of the DEGs and of their human orthologues using public databases.

The term differentially expressed gene, or DEG, is used to describe differential mRNA expression in microarrays. It is important to keep in mind that these measurements not only reflect gene transcriptional activity, but also factors as mRNA stability and degradation. Pathways describe biological phenomena, such as gene regulation, signal transduction, and metabolic processes, in terms of their interactions between biological entities (genes, proteins, metabolites). They are represented by a graph consisting of nodes (biological entities) and edges (interactions). In contrast, a gene set is a collection of genes involved in the same biological phenomenon, and does not use any information about interactions. This study will focus on gene sets representing biological processes from the Gene Ontology (GO) collection.

Molecular network analysis is complementary to pathway analysis as these methods do not rely on pre-defined pathways or gene sets. These tools build a new molecular sub-network based on known molecular interactions from a genome-scale protein-protein interaction network extracted from public databases. As molecular interaction databases cover more interactions than pathway-or gene set databases, molecular network analysis has the potential to provide novel insights on complex interactions (represented graphically by edges) between biological entities (represented by nodes).

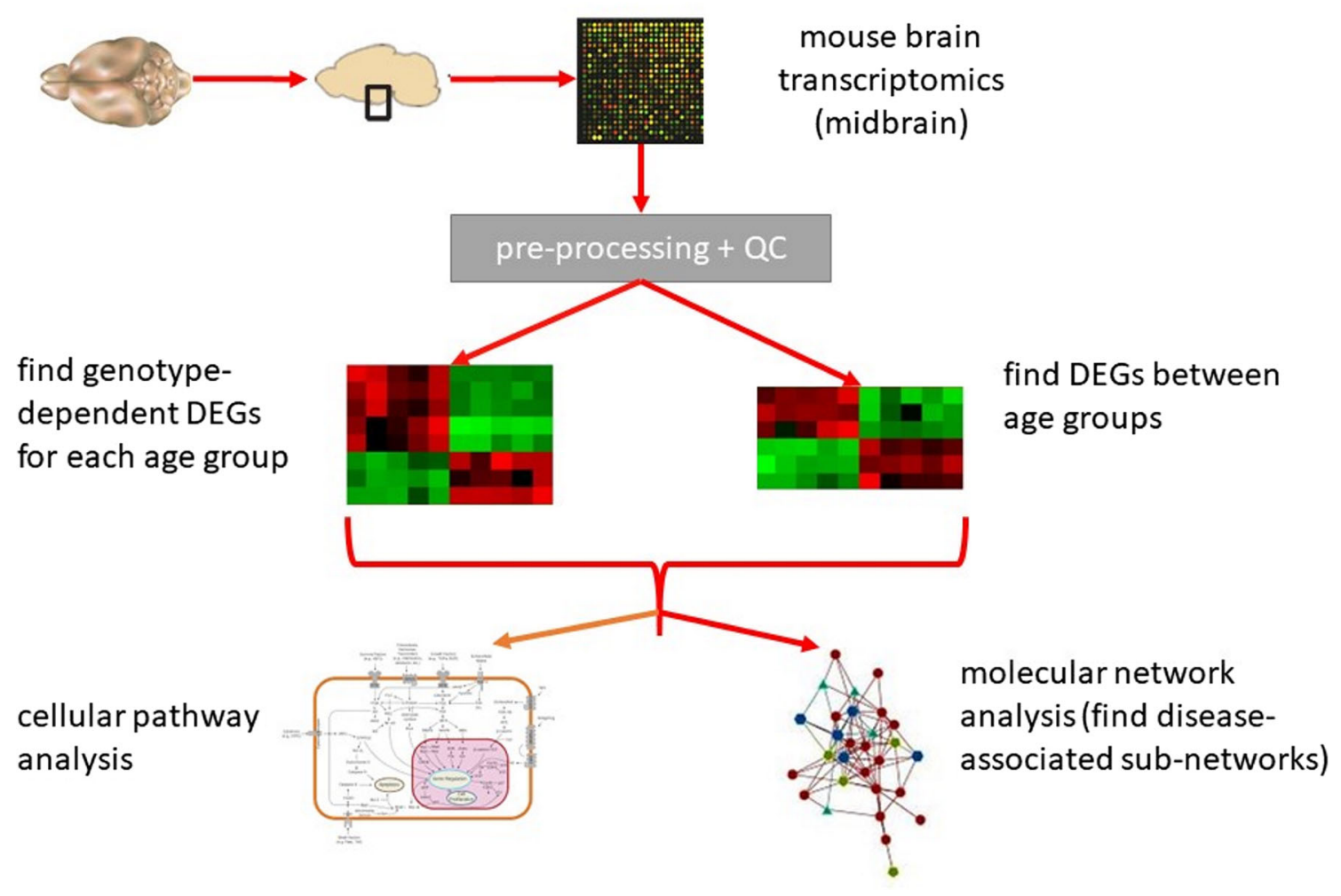

Fig. 1 Data analysis workflow 


\section{Differentially Expressed Genes}

To perform differential expression analysis on the microarray data, pairwise comparisons between groups were conducted with the empirical Bayes moderated $t$-statistic [105] implemented in the Bioconductor limma package (version 3.38.3) [97], with adjustment for multiple testing using the Benjamini-Hochberg procedure [7](false discovery rate $(\mathrm{FDR}) \leq 0.05)$. Since small activity changes in regulatory genes may have important downstream effects [68], we included all genes with statistically significant differential expression (FDR $\leq 0.05$ ), independent of the effect size of the change, i.e., without applying a log-fold change based threshold.

- To identify genotype-dependent DEGs, we performed pairwise comparisons between the two genotypes (WT and HET) at each age (3M, 9M, and 13M).

- To identify age-dependent DEGs that are specifically associated with synuclein transgene expression in HET mice, we first performed pairwise comparisons between consecutive age groups $(9 \mathrm{M}$ versus $3 \mathrm{M}, 13 \mathrm{M}$ versus 9M) for each genotype separately (WT and HET). Since $9 \mathrm{M}$ was the middle age group, we picked this age group to compare with the younger (3M) and older $(13 \mathrm{M})$ group, for both groups separately. We selected the genes that were differentially expressed for both age-group comparisons. Then, we removed age-related DEGs found in both WT and HET from the totality of those found in HET mice, and used the remaining DEGs for pathway, gene set, and molecular network analysis. With this approach, we observed three patterns of gene expression: genes whose expression gradually increased from $3 \mathrm{M}$ to $9 \mathrm{M}$ and then on from $9 \mathrm{M}$ to $13 \mathrm{M}$ (type 1), those whose expression gradually decreased from $3 \mathrm{M}$ to $9 \mathrm{M}$ and then on from $9 \mathrm{M}$ to $13 \mathrm{M}$ (type 2), and those switching in expression directionality between $3 \mathrm{M}$ to $9 \mathrm{M}$ and $9 \mathrm{M}$ to $13 \mathrm{M}$ (type 3). This last type of DEGs could be subdivided in two expression patterns: genes whose expression increased between $3 \mathrm{M}$ and $9 \mathrm{M}$, then decreased between $9 \mathrm{M}$ and 13M (Type 3a), and genes whose expression decreased between $3 \mathrm{M}$ and $9 \mathrm{M}$, then increased between $9 \mathrm{M}$ and 13M (Type 3b).

Significance of the overlap of the DEGs between two comparisons was determined using Fisher's exact test.

The DEGs identified were further paired down with the help of successive translational relevance assessment steps.

\section{Human Orthologues of DEGs}

In a first relevance assessment step, human orthologues for all DEGs were identified and extracted from Ensembl
Biomart database (https://m.ensembl.org/info/data/biomart/ index.html). Orthologues in Ensembl Biomart are determined from gene trees, constructed using one representative protein per gene for each species. The tree is based on sequence alignment, and speciation nodes in the tree correspond to orthologues. These orthologue datasets were the ones used for text mining, pathway, gene set, network, and cellular abundance analyses. Some of the DEGs with human orthologues in Ensembl BioMart were identified as mouse specific in the database NCBI Homologene (https://www.ncbi.nlm.nih.gov/homologene). Table S1 presents an overview of these genes, and also shows expression levels in the brain according to the Human Proteome Atlas (https://www.proteinatlas.org/ ENSG00000069493-CLEC2D/tissue).

\section{Cellular Source for the DEGs}

In a second relevance assessment step, for all DEGs, the brain cell type where the genes show the highest expression was extracted from the Brain RNAseq database (https:// www.brainrnaseq.org/) [133] for both the mouse DEGs and their human orthologues. In case of expression in different cell types, the cell type having the highest transcripts per million (TPM) score for the studied gene was considered as the cell type of expression.

\section{Text Mining and PMI Score}

In a third relevance assessment step, to identify and rank putative functional associations between DEGs and Parkinson's disease (PD) previously described in the literature, a text mining analysis using the Pointwise Mutual Information (PMI) co-occurrence measure was performed [117]. The relative co-occurrences of the human orthologues of the DEGs for the comparisons listed above with the controlled vocabulary Medical Subject Headings (MeSH) term "Parkinson disease" were quantified in fulltext papers from PubMed. For each gene in the list of DEGs, the PMI score is calculated as follows:

$P M I=\frac{\log p(x, y)}{p(x) \cdot p(y)}$

where $p(x)$ is the proportion of full-text papers in PubMed that match the gene, $p(y)$ is the proportion of full-text papers in PubMed that match the MeSH term "Parkinson Disease," and $p(x, y)$ is the proportion of full-text papers in PubMed that match the gene and the MeSH term "Parkinson Disease." PMI calculates how much more the gene and the MeSH term "Parkinson Disease" co-occur than expected by chance. Genes with a higher PMI score display more frequent relative co-occurrences with the MeSH term "Parkinson disease" in relation to the occurrences of the 
individual terms in PubMed, pointing to candidate genedisease associations for which specific literature references can be retrieved (see "Results" section).

\section{Comparability of the Mouse Model to Human Data}

In a fourth relevance assessment step, to test the relevance of the mouse model to study molecular events leading to an early-PD like phenotype, the human orthologues of the lists of DEGs between genotypes (HET versus WT) obtained from the mouse data for each age (3M, 9M, 13M) were compared with the list of DEGs from a recent metaanalysis of transcriptomics data from post-mortem brain samples of PD patients and controls conducted by Kelly et al. [61]. Thus, with these 4 relevance assessment steps, we evaluated whether the mouse model data can provide an adequate reflection of the alterations associated with early PD progression.

\section{Pathway and Gene Set Analysis}

To detect molecular pathway and gene set alterations associated with the progression of PD-like pathology in HET mice, an enrichment analysis was conducted using the Web-based software GeneGO MetaCore ${ }^{T M}$ (https:// portal.genego.com/). The input table was the list of human orthologues of the genes identified as DEGs in the mouse dataset, with adjusted $p$ value $\leq 0.05$, together with the logarithmic fold change to determine the expression directionality. Because small-effect size changes in transcription factors may be relevant for the downstream analyses [68], we did not apply a log-fold change threshold. In case several mouse genes had the same human orthologue, the gene having the highest average expression was taken as representative. The $p$ values for the pathways were corrected for multiple hypothesis testing using the approach by Benjamini and Hochberg [7] and an FDR threshold of 0.05 was applied. Only pathways with size between 5 and 500 network objects (gene products), including at least 3 network objects from the data (DEG list), were considered. Furthermore, pathways whose function is not known in the brain, but only in other organs, were removed.

To keep in line with the analysis of DEGs that had different patterns of expression changes (see above), a separate pathway and gene set analysis was performed for:

- Genotype-dependent changes: the DEGs between HET and WT, within each age group.

- Age-dependent changes in HET only: genes whose expression increases with age (type 1), genes whose expression decreases with age (type 2); genes whose expression switches directionality (type 3a: increased between the $3 \mathrm{M}$ and $9 \mathrm{M}$, decreased between $9 \mathrm{M}$ and $13 \mathrm{M}$; type3b: decreased between the $3 \mathrm{M}$ and $9 \mathrm{M}$, increased between $9 \mathrm{M}$ and $13 \mathrm{M}$ ).

Age-dependent pathways and gene sets that were identified by this approach were named the same way as the DEGs they were based on (type 1, type 2, type $3 \mathrm{a}$ and $b$ ), based on whether they were upregulated (type 1), downregulated (type 2), or switching their regulation directionality as the HET mice aged (type $3 a$ and $3 b$ )

\section{Network Analysis}

Network analysis investigates altered interactions between key components of different pre-defined pathways or biological processes. It does so by mapping each list of DEGs to a genome-scale protein-protein interaction network. Analysis of the custom networks build in this way, called molecular sub-networks, provides complementary information to the pathway analysis on associations between gene sets and biological processes.

In our study, molecular sub-networks were determined by analyzing the lists of DEGs that were used for the pathway analyses with the GeneGO MetaCore ${ }^{T M}$ default "Analyze network"(AN) procedure. Using information on molecular interactions and canonical pathways, the procedure identifies and ranks altered molecular sub-networks surrounding the mapped gene products corresponding to the DEGs. The resulting molecular sub-networks include a number of additional proteins and protein complexes that interact directly or indirectly with the gene products of DEGs. This algorithm first builds a large network by gradually expanding a network around every gene product from the DEGs, then it gives priority to proteins and protein complexes having the highest connectivity (incoming and outgoing edges) with the initial protein or protein complex. The larger network is divided into a maximum of 30 sub-networks of maximum size 50 (default settings), so that each edge only occurs in one sub-network. Nodes may be part of different subnetworks but connected by different edges. A $p$ value for the intersection of the gene products from the list of DEGs and the nodes in the sub-network was calculated by Fisher's exact test. Only networks including at least 3 gene products of the input list were selected.

\section{Results}

\section{Transgene Expression Levels in BAC-Tg3(SNCA*E46K) “Line 3" Mice}

The levels of SNCA transgene RNA, of murine Snca RNA, and of total RNA from both (murine and human), all measured by RT-qPCR, for the ventral midbrain, are shown 

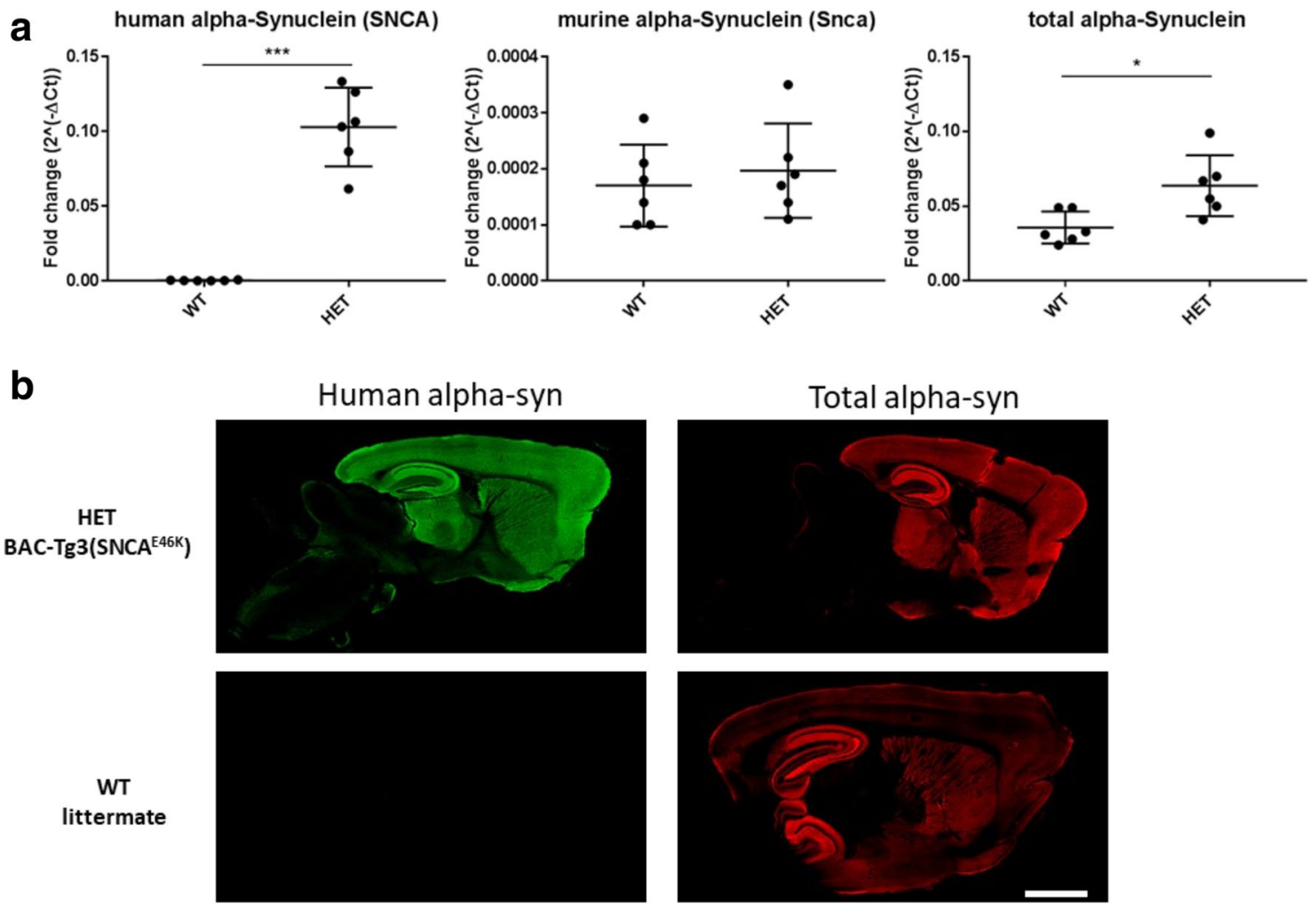

Fig. 2 Alpha-synuclein expression in BAC-TG3 $\left(S N C A^{E 46 K}\right)$ "Line 3" mouse brains. RT-PCR measurements (a) showed: that SNCA was detected in all HET mice, that the levels of RNA for murine Snca were similar between HET mice and WT littermates, and that the levels of overexpression (measured by levels of total RNA for both SNCA and Snca) were about 1.8 -fold $(78 \%)$ in ventral midbrain of HET mice

in Fig. 2a. Transgene SNCA RNA was detected in all mice that tested positive for the transgene by genotyping (HET mice), but not in wild-type (WT) littermates. Levels of murine Snca RNA were not significantly different between mice of the two genotypes. Levels of total alpha-synuclein RNA indicate an approximately 1.8 -fold transgene expression in HET mice compared with that in WT littermates. Taken together, this indicates that the increased overall $\alpha$-syn RNA expression in HET was due to transgene. Alpha-synuclein proteins, human or total protein, were revealed by immunofluorescence (Fig. 2b). Transgenic human alpha-synuclein was localized mainly in the neocortex, hippocampus, thalamus, striatum, and midbrain areas (including $\mathrm{SN}$ ), and its distribution roughly matched that of endogenous alpha-synuclein in WT mice.

\section{Age-Dependent Neurodegeneration in the Dorsal Striatum but Not in the Substantia Nigra}

To determine $\alpha$-syn transgene-induced effects in the nigrostriatal circuit in HET mice at different ages, we measured compared to that of WT littermates. $* * * p<0.0001, * p<0.05$ by unpaired Student's $T$ test. Fluorescent immunostaining showed that the transgene human alpha-synuclein (panels in left column) shows roughly the same regional distribution than the endogenous murine alpha-synuclein (panels in right column). Scale bar (b) $=1.4 \mathrm{~mm}$

the integrity of TH-positive axons and DAT-positive synapses in the dorsal striatum, and estimated the number of $\mathrm{TH}$ positive neurons in the SN in HET and WT control mice.

Our results are shown in Fig. 3. We found an agedependent decline of TH-positive axons (Fig. 3a) and in DAT-positive synaptic terminals (Fig. 3b) in HET mice. We did not observe loss of TH-positive neurons in the SN (Fig. 3c) in these mice. Importantly, striatal loss of TH-positive axons in 13M old HET mice significantly correlated negatively with relative levels of transgenic $\alpha$-syn $(r=-0.94, p=0.017$, by Pearson's). This indicates that degeneration of TH-positive axons in the dorsal striatum is caused by human $\alpha$-syn, and that the neurodegenerative phenotype of BAC-Tg3(SNCA ${ }^{E 46 K}$ ) mice is not a consequence of a transgene insertion artefact. Because striatal degeneration without measurable loss of TH-positive nigral neurons is a feature of incipient Lewy body disease [24, 29] and early PD [63], we decided to use our model as a tool to study gene expression changes in the ventral midbrain leading up to the degeneration in the dorsal striatum. 

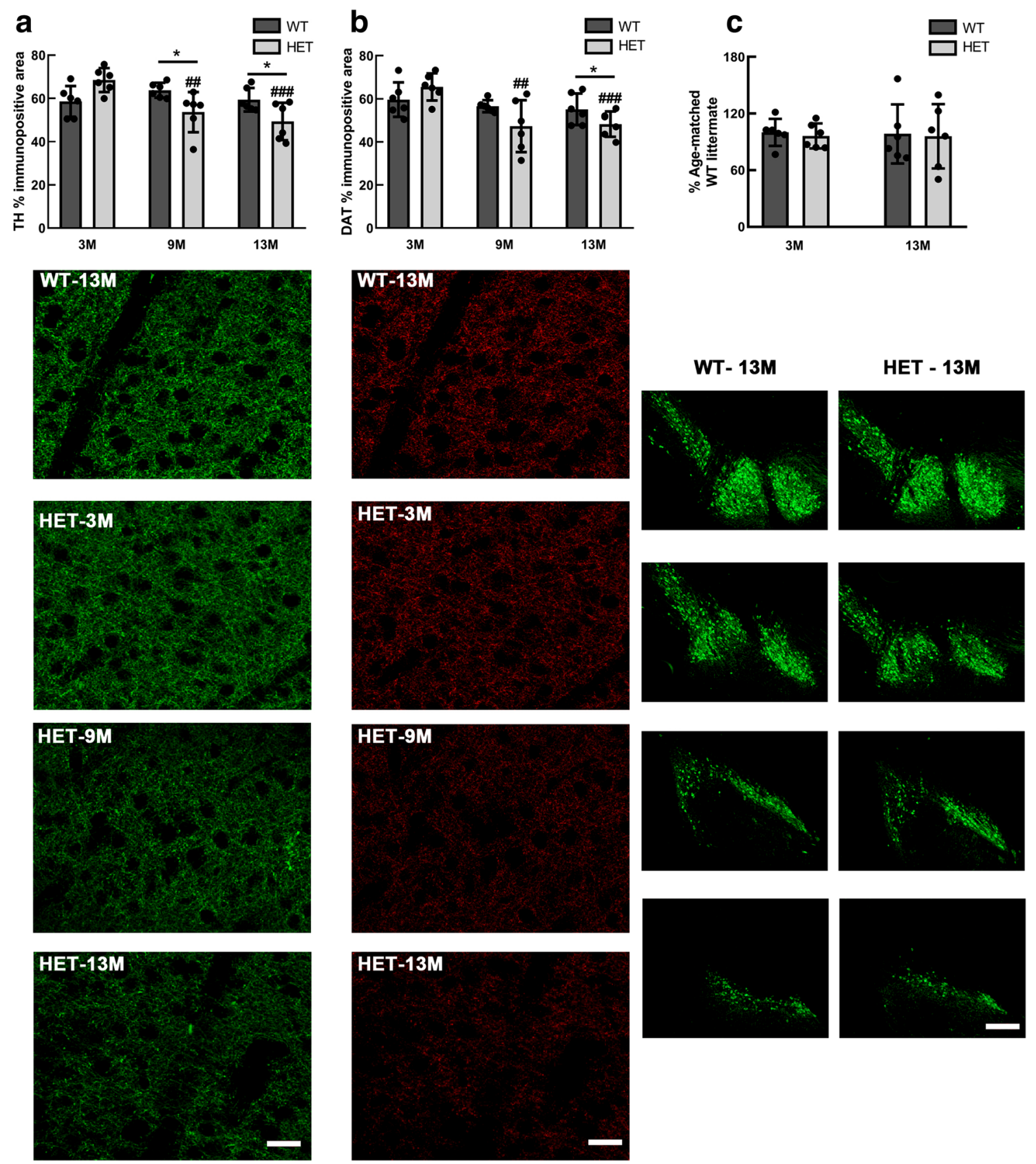

Fig. 3 Age-dependent degeneration in the dorsal striatum but not the substantia nigra, in heterozygous (HET) BAC-Tg3( $\mathrm{SNCA}^{E 46 K}$ ) mice compared with that in littermate wild-type (WT) controls. Measurements for Tyrosine-hydroxylase (TH, green channel) and dopamine transporter (DAT, red channel) were performed as described in "Material and Methods." Two-way ANOVA followed by post hoc tests was used for statistical analysis. $N=6$ mice per age group and

\section{Uncovering and Assessing the Relevance of Genotype-Dependent and Age-Dependent DEGs}

Table 1 shows the number of DEGs for each comparison used in this study to uncover genotype- and agedependent DEGs, together with the corresponding number genotype. * symbol for $p<0.05$ in genotype comparisons, \#\# symbol for $p<0.01$, and \#\#\# for $p<0.001$ when comparing 9M HET and 13M HET mice, respectively, to 3M HET mice. Values for TH-positive neurons in the $\mathrm{SN}$ were normalized to WT controls for each age group. Different levels of the SN, from medial to lateral, are shown. Scale bars: $30 \mu \mathrm{m}$ for immunostaining panels in columns $\mathrm{A}$ and $\mathrm{B}$, and 100 $\mu \mathrm{m}$ for immunostaining panels in column $\mathrm{C}$

of human orthologues according to the public repository Ensembl BioMart (https://m.ensembl.org/info/data/biomart/ index.html). We first identified genotype-dependent (HET mice versus WT mice) DEGs at each age. The approach is detailed in the "Materials and Methods" section. We observed 584 DEGs in $3 \mathrm{M}$ mice, 5 in $9 \mathrm{M}$ mice, and none in 
Table 1 Number of differentially expressed genes (DEGs) identified for the different comparisons, together with the corresponding number of human orthologues according to Ensembl BioMart (https://m.ensembl.org/info/ data/biomart/index.html)

\begin{tabular}{lll}
\hline Comparison & Number of mouse DEGs & Number of human orthologues \\
\hline 3M HET vs 3M WT & 741 & 584 \\
9M HET vs 9M WT & 7 & 5 \\
13M HET vs 13M WT & - & - \\
9M HET vs 3M HET & 1986 & $1401^{*}$ \\
13M HET vs 9M HET & 1837 & $1532^{* *}$ \\
9M WT vs 3M WT & 6574 & $4526^{* * *}$ \\
13M WT vs 9M WT & 2002 & $1664^{*}$ \\
\hline
\end{tabular}

*2 genes are identified as "only expressed in mice" in NCBI Homologene (https://www.ncbi.nlm.nih.gov/ homologene)(see Table S1); **3 genes are identified as "only expressed in mice" in NCBI Homologene (see Table S1); ${ }^{* *} 10$ genes are identified as "only expressed in mice" in NCBI Homologene, 4 of them have no reported brain expression, based on Human Protein Atlas (https://www.proteinatlas.org/ ENSG00000069493-CLEC2D/tissue) (see Table S1)
$13 \mathrm{M}$ mice. There was no overlap between the DEGs in 3M mice and those in 9M mice (Fig. 4a).

Then, to uncover age-associated gene expression changes specifically driven by $\alpha$-syn overexpression in our model, we used a stringent selection approach to exclude gene expression changes associated with age in both HET mice and their WT littermates. Our approach is described in the
"Materials and Methods" section, and visualized in the Venn diagrams of Fig. $4 \mathrm{~b}$.

Since the $9 \mathrm{M}$ was the middle age group, we chose this age group, to compare, in each genotype separately, the younger age group (3M) and the older age group (13M) to. Thus for each of the two genotypes, we obtained two sets of DEGs (HET mice: 9M versus 3M: 1401 DEGs,

\section{a Genotype-dependent differentially expressed genes}

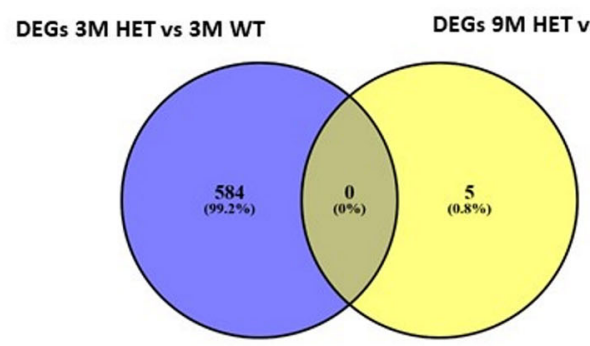

\section{b Age-dependent differentially expressed genes}

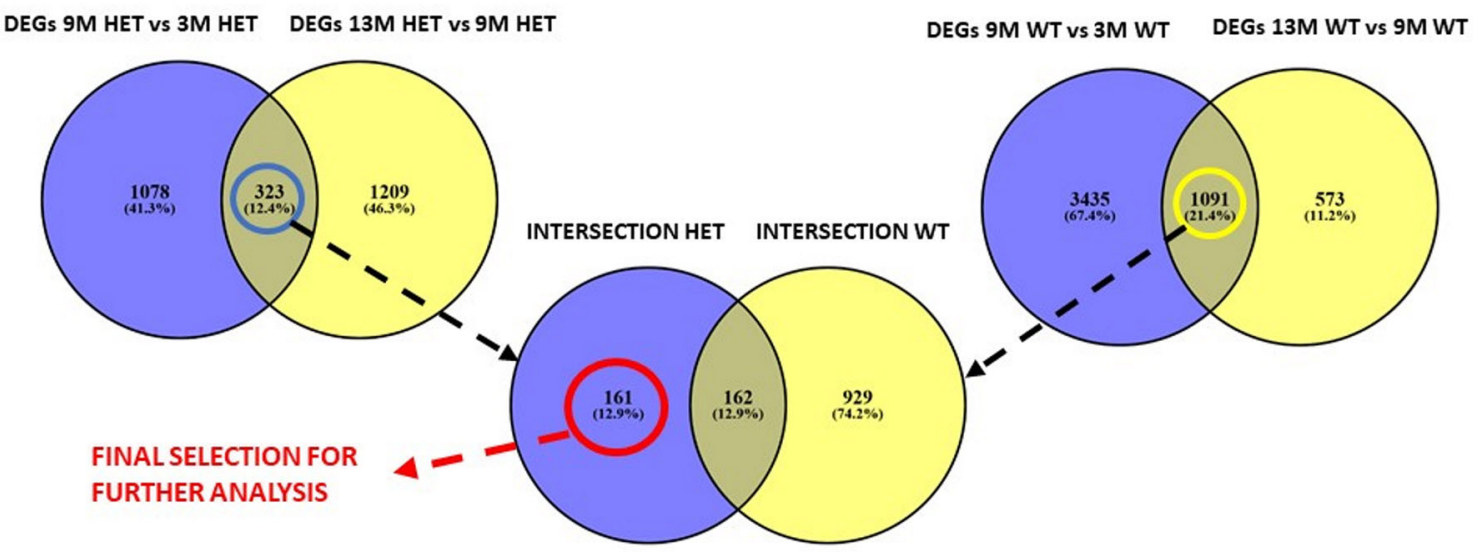

Fig. 4 (a) Overlap of differentially expressed genes for the agematched mice of different genotypes (upper panel), (b) Differential expression across ages for HET mice (lower panel,left), WT mice (lower panel, right), overlap intersections HET (323 genes), and WT (1091 genes) in previous figures (lower panel, middle) 
13M versus 9M: 1532 DEGs; WT mice: 9M versus 3M: 4526 DEGs, 13M versus 9M: 1664 DEGs). For each genotype, these comparisons yielded a significant intersection of DEGs: 323 for HET mice (intersection HET, Fisher's exact test $p$ value $=9.27 \mathrm{e}-17$ ), and 1091 for WT mice (intersection WT, Fisher's exact test $p$ value $=1.78 \mathrm{e}-74$ ). These were the genes, for each respective genotype, whose expression changed continuously as the mice aged. To extract the genes whose expression changed continuously over age in HET mice only, we looked at the intersection of the two sets of age-dependent DEGs (intersection HET and intersection WT). The genes whose expression changed continuously over age in HET mice only, a total of 161 DEGs, were selected for further analysis.

\section{Genotype-Dependent DEGs, Their Relevance (PMI scores), and Cellular Sources}

Table 2 shows the top 10 DEGs with positive PMI scores in 3M HET mice versus age-matched WT littermates, and the one DEG with a positive PMI score in 9M HET versus agematched WT littermates, ranked in terms of their PMI textmining association scores with the MeSH term "Parkinson Disease."

DEGs in 3M HET versus 3M WT The genotype-dependent DEGs at $3 \mathrm{M}$ are expressed across all types of brain cells (Fig. 5a). For $30 \%$ of DEGs, the main cell type they were expressed in is the same in mouse and human.

Out of the 584 identified human orthologues, 75 genes had a positive PMI score. In the top 10, 9 were found to be increased in HET versus WT. Four of these genes have previously been associated to $\alpha$-synuclein pathology: TMEM230 [71], TMEM175 [54], B4GALNT1 [122], and SCAMP5 [126]. TMEM230 gene product is involved in the trafficking of synaptic vesicles and retromer components [62] and mutations in this gene have been linked to autosomal dominant PD [25]. TMEM175 has been identified as a PD risk locus [84]. It is a $\mathrm{K}(+)$ channel regulating lysosomal function [17]. Its deficiency in neuronal cells impairs lysosomal and mitochondrial function, and increases susceptibility to $\alpha$-synuclein toxicity [54]. As an ion channel, it is basically a druggable target. B4GALNT1 is involved in the synthesis of GM1 ganglioside, which interacts with $\alpha$-syn to inhibit its fibrilization [122] and promote its clearance [43]. In addition, a PD-like phenotype has been observed in B4GALNT1 knockout mice [67]. Thus, the increase of B4GALNT1 and TMEM175 in 3M HET mice may indicate an attempt to counteract abnormal $\alpha$-syn. SCAMP5 has been shown to modulate calcium-dependent exocytosis by interacting with SNAREs [135] and $\alpha$-syn secretion via exomes in vitro [126]. The gene products of two DEGs, measured in blood, have been reported to be associated with PD: PSMC4 (26S proteasome AAA-ATPase subunit Rpt3, a component of the proteasome complex) [83] and COPZ1 (COPI coat complex subunit zeta 1 , encoding a subunit of the cytoplasmic coatamer protein complex, which is involved in autophagy and intracellular protein trafficking) [99].

DEGs in 9M HET Versus 9M WT At 9M, both the number of DEGs and the number of cell types where they are expressed decreased compared with 3M (Fig. 5a). For two of the five DEGs, the main cell type where they are expressed is the same in mouse and human. Furthermore, for the human orthologues, microglia appear, whereas these cells do not appear in the mouse chart. The human microglial orthologue $(C R A B P 2)$ is associated with a gene expressed in neurons in mice (Crabp2). Of the five DEGs (OMD, ACTA2, CRABP2, $R A R B, S L C 22 A 8)$ in 9M HET versus 9M WT mice, only $O M D$ (Osteomodulin) has a positive PMI score (Table 2, middle part). OMD expression is enhanced in 9M HET mice compared with that in WT, and its protein level has been shown to be increased in plasma from PD patients, and therefore it could be a potential biomarker [92].

\section{DEGs in 13M HET versus 13M WT No DEG observed.}

\section{Age-Dependent DEGs, Their Relevance (PMI Score), and Cellular Sources}

Among the 161 age-dependent DEGs being driven by $\alpha$ syn overexpression (Fig. 4b, Fig. S2), 3 types of expression patterns were observed (see "Methods").

Genes with Age-Dependent Increase in Expression (Type 1) These changes may point to key drivers of disease progression, or, conversely, to compensatory and protective mechanisms. Figure $5 \mathrm{~b}$ shows the brain cell type where these DEGs show the highest expression. When comparing mouse and human, $40 \%$ of the DEGs were expressed in the same brain cell type. Of the 5 type 1 DEGs, none has a positive PMI score. The gene product of one of the DEGs though, FAS, has been associated with neurodegeneration in PD, but with some conflicting evidence. One of its ligands which promotes cell death, FAS-associated factor 1 (FAF1), is the product of a gene that is associated with a form of late-onset PD [47], is increased in PD cortex, and exacerbates the response to $\mathrm{PD}$ toxin in vitro [8]. Moreover, the PD-associated mutated LeucineRich-Repeat Kinase 2 (LRRK2) was reported to promote neuronal cell death in vitro via a mechanism involving death adaptor FAS-associated protein (FADD), and caspase8 activation [50]. Absence of FAS partially protected mice against 1-methyl-4-phenyl-1,2,3,6-tetrahydropyridine (MPTP)-induced dopaminergic cell loss in the SN in one 


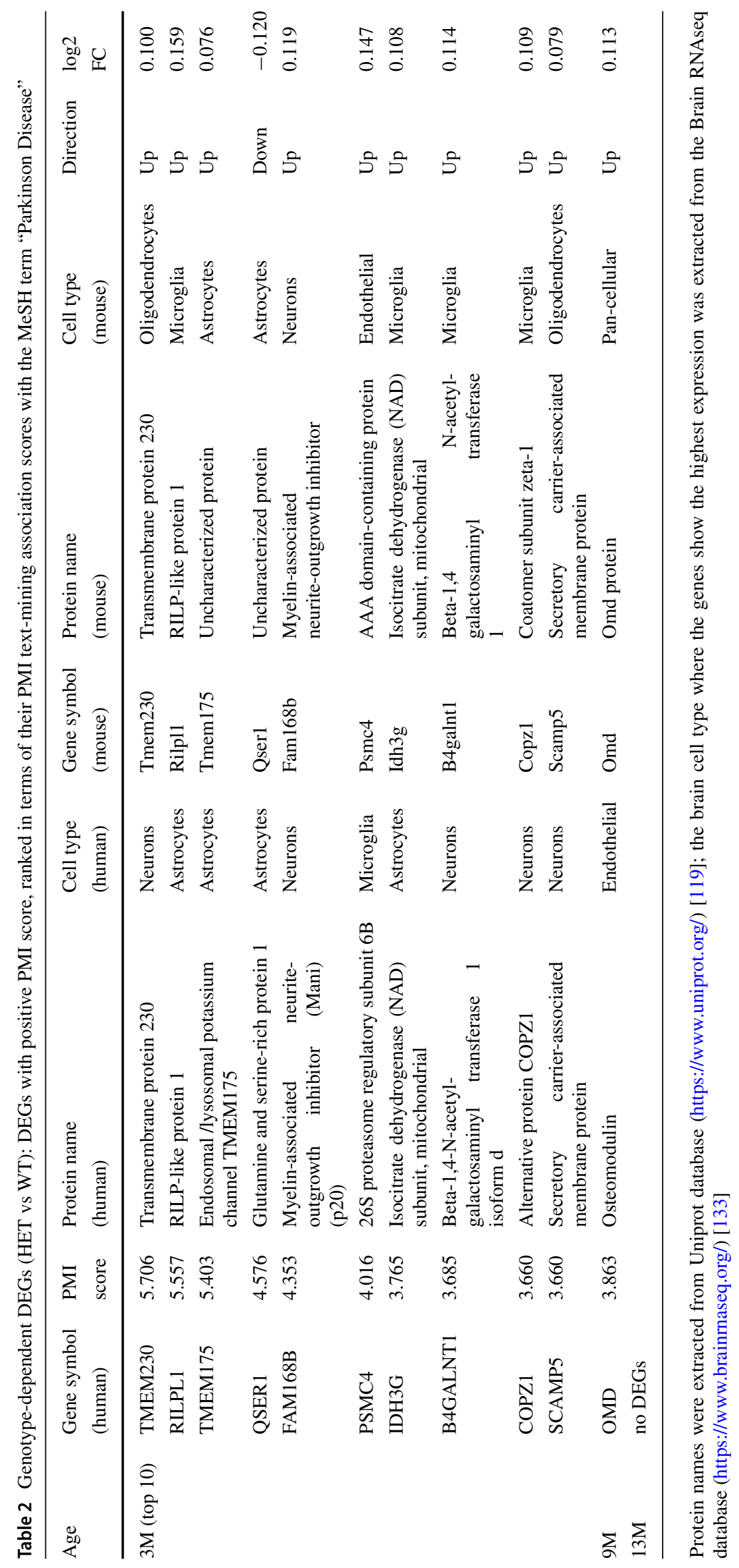




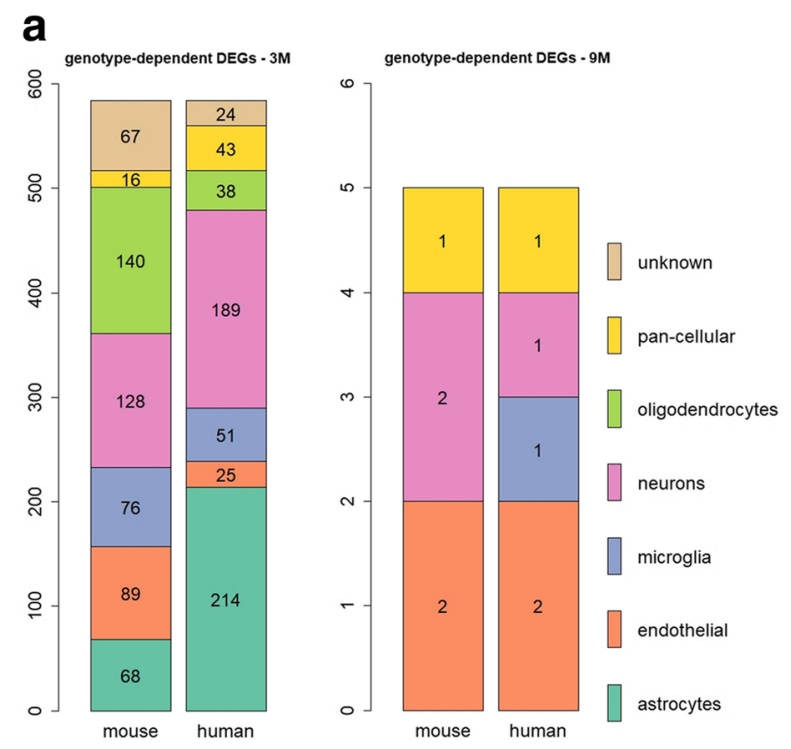

b
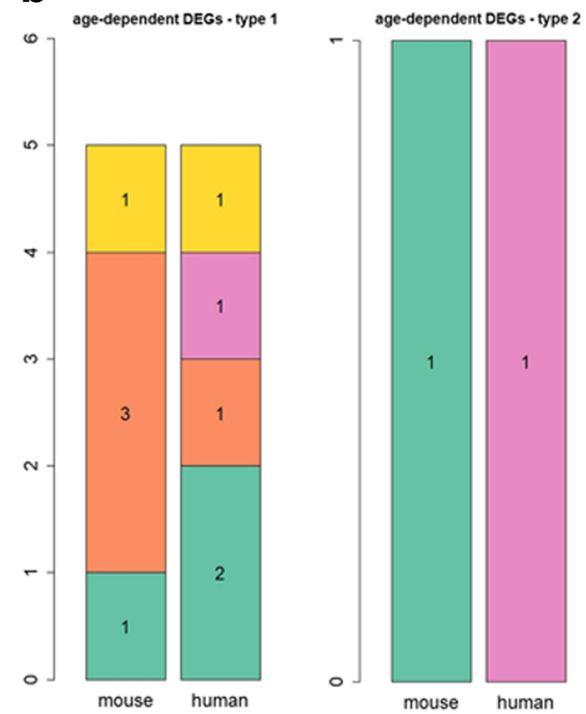

Fig. 5 DEGs-brain cell type where the genes show the highest expression (extracted from the Brain RNAseq database (https://www. brainrnaseq.org/) [133]). (a) Genotype-dependent DEGs: left panel: $3 \mathrm{M}(30 \%$ same cellular source); right panel: $9 \mathrm{M}$ (40\% same cellular source). (b) Age-dependent DEGs: upper left panel: type 1-DEGs increasing with age (40\% same cellular source); upper right panel: type

study [45], whereas it rendered them more susceptible to it in another [65]. Overall, most of the evidence points to the harming effect of FAS involvement in a PD context, and interfering with the FAS pathway could open up new venues for therapeutic intervention.

\section{Genes with Age-Dependent Decrease in Expression (Type 2)}

These changes may reflect the injury associated with disease progression, and could be potential targets or biomarkers candidates. Only one gene showed decreased expression

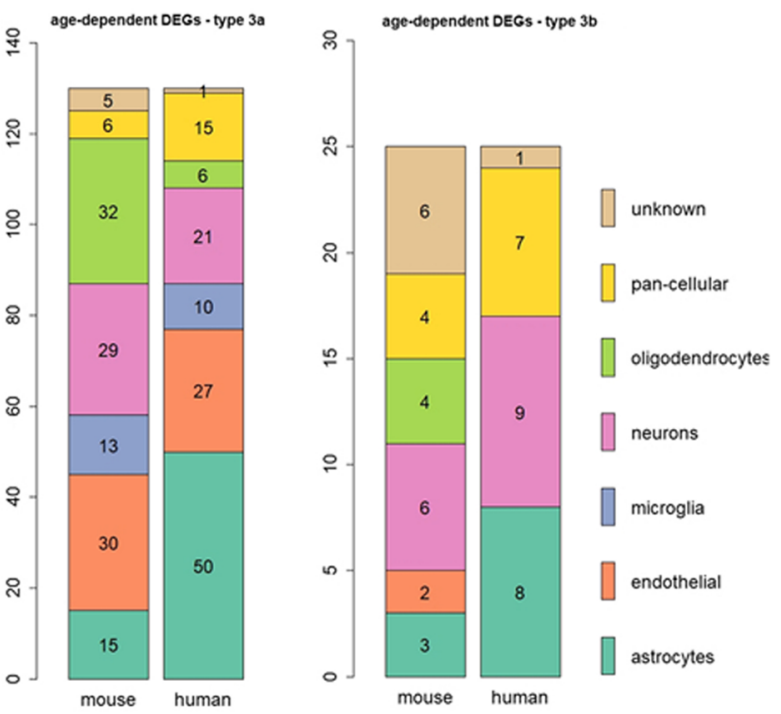

2-DEGs decreasing with age (only 1 DEG, different cellular source between mouse and human); lower left panel: type 3a-DEGs with increased expression between $3 \mathrm{M}$ and $9 \mathrm{M}$, and decreased expression between $9 \mathrm{M}$ and 13M (28\% same cellular source); lower right panel: type $3 \mathrm{~b}-$ DEGs with decreased expression between $3 \mathrm{M}$ and $9 \mathrm{M}$, and increased expression between $9 \mathrm{M}$ and $13 \mathrm{M}$ ( $40 \%$ same cellular source)

with age: $U B P 1$, a protein coding gene whose product is a transcriptional activator [114]. While for mice this gene is expressed in astrocytes, the human orthologue is expressed in neurons (see Fig. 5b). No relationship between $U B P 1$ and PD has previously been reported in the literature according to the PMI text-mining analysis.

Genes Switching in Directionality with Age (Types 3a and 3b) These DEGs may help to shed some light into more complex adaptive and disease-stage-dependent processes 
involving multiple aspects of disease progression, and will point the way to future studies that help shed light into hitherto unknown facets of PD.

We identified 130 type 3a DEGs that have increased expression between $3 \mathrm{M}$ and $9 \mathrm{M}$, then decreased expression between $9 \mathrm{M}$ and 13M (Fig. S2). Twenty-eight percent of genes expressed the same main brain cell type in mouse and human. Out of the 130 type 3a DEGs, 18 have a positive PMI score. Table 3 shows the top 10 type $3 \mathrm{a}$ DEGs, ranked in terms of their PMI text-mining association scores with the MeSH term "Parkinson Disease." Among these, $S V 2 C$ modulates dopamine release, and is disrupted in transgenic PD models and in PD, but not in other neurodegenerative diseases [31]. The ADORA2A receptor is an GPCR for adenosine, whose disruption is protective in a $\alpha$-syn transgenic model of PD [57], and has been suggested as a potential drug target [19]. Lower expression of $A K 4$, a mitochondrial phosphotransferase, has been observed in the late PD [37]. GPR88, a Gi/o coupled orphan receptor, has been proposed as a PD target, due to its association with D2 receptor signaling and its involvement in cognitive and motor functions [127]. Finally, RILPL2 is involved in ciliogenesis linked to downstream LRRK2-dependent phosphorylation of Rabs [110]. Mutated forms of LRRK2 have been reported to impair ciliogenesis as well as its associated neuroprotective Sonic hedgehog signalling [28].

We identified 25 type $3 \mathrm{~b}$ genes, that have decreased expression between $3 \mathrm{M}$ and $9 \mathrm{M}$, then increased expression between $9 \mathrm{M}$ and $13 \mathrm{M}$ (Fig. S2). Forty percent of these $3 \mathrm{~b}$ genes expressed the same main brain cell type in mouse and human. Like type $3 \mathrm{a}$ genes, $3 \mathrm{~b}$ genes were expressed by various brain cells (Fig. 5b). Six out of 25 type $3 \mathrm{~b}$ DEGs had a positive PMI score (Table 3). Two of these genes have reported association with PD: $M D G A 2$, whose product functions as a regulator of axonal growth [55], has a SNP that may be associated with earlier onset in familial PD [66]. CALB1, coding for calbinin-1, a protein involved in buffering intracellular calcium, has a SNP associated with sporadic PD [82].

A majority of type $3 a$ and type $3 b$ DEGs were similar in their expression levels in 3M HETs and 13M old HETs, indicating that they transiently increased, or respectively, decreased in 9M old HETs, before returning to the initial expression level. The only exception were 4 type 3a DEGs (OSR1, SLC22A6, PTN, and SLC6A20), whose expression was lower in 13M HETs than in 3M HETs.

A majority of age-dependent DEGs were switching their expression direction, which was one of the most intriguing observations of our study. We believe this is not an artifact, but a true biological phenomenon. As the mean absolute difference in variance in gene expression between consecutive age groups is very low (Table S2), we can exclude that this observation results from increased variance in the data.
Furthermore, we believe that the comparatively lower number of DEGs that increases (type 1) or decreases (type 2) with age in HET mice is also not due to those genes reaching an upward or downward plateau in expression level before the HET mice reach 13M of age. Indeed, the median $\log 2$ expression of the genes increasing between $3 \mathrm{M}$ and 9M in HET mice was lower than 1 (Fig. S3), and, similarly, the median $\log 2$ expression of genes decreasing between $3 \mathrm{M}$ and $9 \mathrm{M}$ in HET mice was only slightly higher than 1 (Fig. S3). This indicates that the age-dependent increasing expression of type 1 DEGs does not plateau, and, similarly, age-dependent decreasing expression of type 2 DEGs does not bottom out before HET mice reach 13M. In addition, the 9M old group of HET and WT littermate control mice was derived from the same initial breeding cohorts as their $3 \mathrm{M}$ and $13 \mathrm{M}$ old counterparts, and the study groups were randomly assigned to the different age groups after weaning and genotyping, thus excluding an inadvertent strain effect due to an error in breeding setup. Hence, these findings indicate that the age-dependent switch in expression direction of type $3 a$ and type $3 b$ DEGs is a true biological phenomenon that is likely to reflect complex interactions in different responses to the chronic injury in response to $\alpha$-syn overexpression. To the best of our knowledge, such an observation has not been found previously in other PD models.

\section{Pathway and Gene Set Analysis}

Comparative pathway and GO analyses between a disease model and its control reveals molecular and cell biological processes in cells that are altered by disease initiation and progression.

In this study, we were interested in identifying pathways and GO biological processes altered by genotype (SNCA transgene), or changing with age in the context of $\alpha$-syn overexpression in our model.

\section{Genotype-Dependent Pathway/GO Changes}

Pathways/GO Biological Processes in 3M HET Versus 3M WT Table S3 presents the top 10 out of the 50 identified significantly altered pathways in the $3 \mathrm{M}$ HET mice versus the $3 \mathrm{M}$ WT mice. Top pathways altered are related to serotonin and glutamate neurotransmissions, which are known to regulate firing activity of $\mathrm{SN}$ dopaminergic neurons [79, 134]. Interestingly, a pathway related to G-protein-coupled receptor (GPCR) signaling ("G-protein signaling - Regulation of Cyclic AMP levels by ACM") was identified. Synucleins (including $\alpha$-syn) are substrates for GPCR kinases [94]. Dopamine D2 receptors, which are present on SN neurons, are also GPCRs [23]. GPR55 


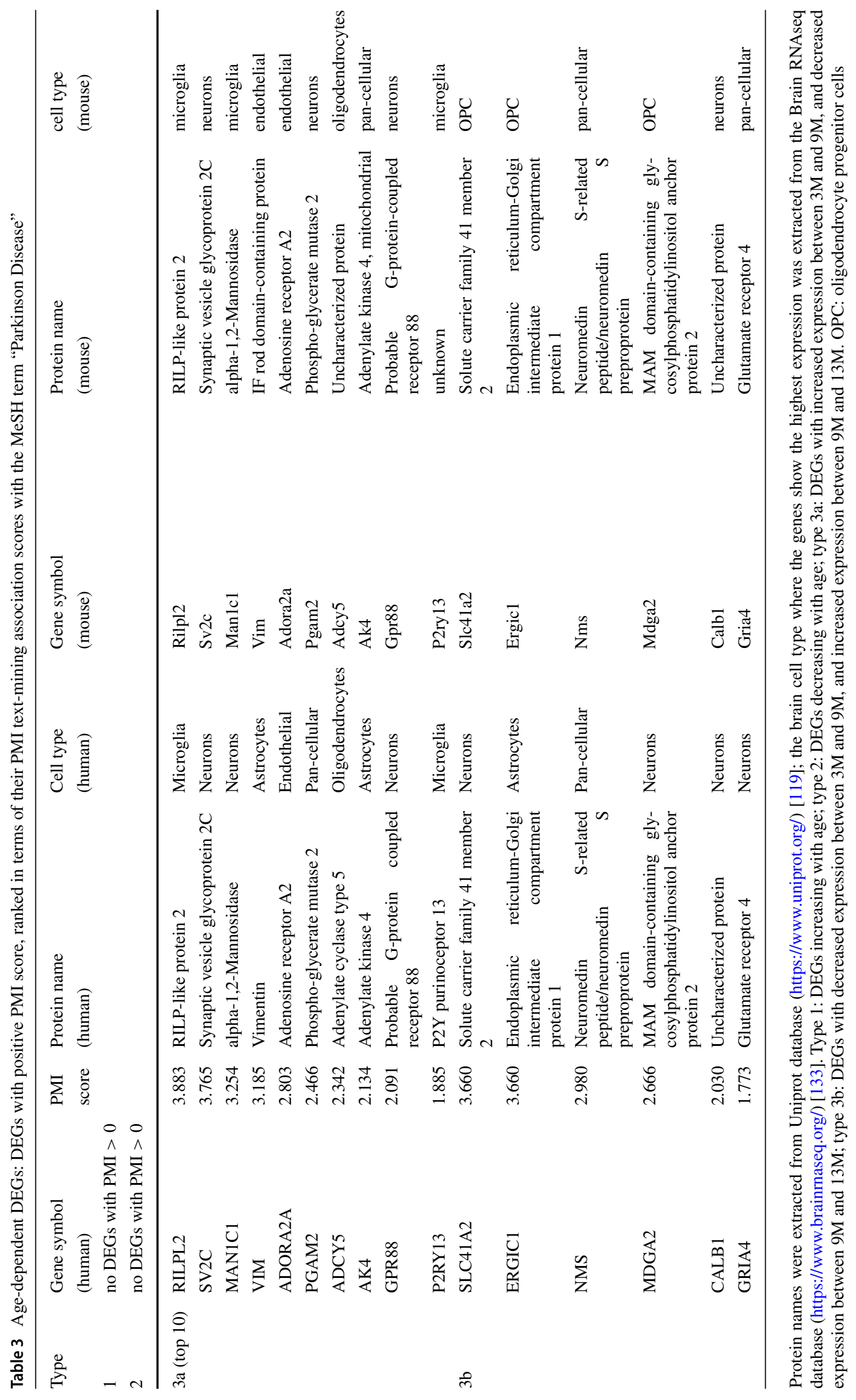


and GPR37 are GPCR involved in modulating functions of SN neurons, and their absence in mice leads to motor impairments [73, 121]. The prostaglandin (PGE2) pathway, an inflammation-related pathway involved in neurodegenerative diseases [69], was identified. Wnt/Betacatenin and NF-kB pathways were also altered, and are known to modulate dopaminergic cell differentiation and maintenance, as well as to regulate cytokine release from immune cells [74].

Finally, we identified 43 significantly altered GO terms, of which the top 10 (Table S4) included biological processes related to inorganic cation homeostasis, synaptic signaling, and memory.

\section{Pathways/GO Biological Processes in 9M HET Versus 9M} WT While we found no altered pathway between 9M HETs and their WT littermate controls, we found 66 GO biological processes that differed between them. The top 10 GO terms (Table S4) included developmental processes (e.g., the process "GO:0061448: connective tissue development"). Interestingly, some altered biological processes are associated with regulation of actin filamentbased movement, which has been reported to be regulated by $\alpha$-syn [33, 107]. Another altered biological processes related to the ERK1/2 pathway, which is linked to PD pathological processes [12].

\section{Pathways/GO Biological Processes in 13M HET Versus 13M} WT Since no DEGs were observed between 13M HETs and their WT littermate controls (see above), no altered pathway or GO was observed either.

\section{Age-Dependent Pathway/GO Changes}

We used a similar nomenclature (type 1, type 2, type 3a and $3 b$ ) for the classification of age-dependent pathway and GO changes as we used for DEGs (see above).

\section{Pathways/GO Terms with Age-Dependent Upregulation} (Type 1) None identified.

\section{Pathways/GO Terms with Age-Dependent Downregulation} (Type 2) None identified.

\section{Age-Dependent Pathways/GO Terms Switching Between} Up-/Downregulation or Vice Versa (Types $3 a$ and $3 b$ ) The top 10 out of 50 pathways first upregulated, and then downregulated (type 3a, Table S5), were involved in cell differentiation, migration processes, and GPCR signaling. Interestingly, the pathways identified share signaling components with pathways involved in TGF-beta and PI3Kmediated neuroprotection of dopaminergic neurons $[64,98$, $103,125]$, and with pathways involved in lipid metabolism and immunomodulation (such as lipoxins [76]). Altered GPCR-related pathways were linked to Nociceptin $(N O P)$, C-C chemokine-receptor 1 (CCRl), and Sphingosine-1 phosphate-receptor $1(S 1 P I)$ signaling. NOP is an inhibitory neuropeptide which may promote $\mathrm{SN}$ less loss in PD: its genetic deletion protects SN neurons against MPTP in mice, and the inhibition of its receptor protects the same neurons in a rat model of $\alpha$-syn toxicity [4]. CCRI is typically microglial and its product participates in the recruitment of immune cells, but it is also expressed in the ventral midbrain during development, where it is involved in neuronal differentiation of DA neurons [32]. SIP1 is uncoupled from an inhibitory G-protein by extracellular $\alpha$ syn, and may therefore play a role in intracellular $\alpha$-syn accumulation [132].

A majority of the top 10 out of the $67 \mathrm{GO}$ terms we detected (Table S6) are involved in GPCR signaling, purinergic signalling, and development.

No pathways, but $117 \mathrm{GO}$ terms first downregulated, then upregulated (type $3 b$ ), were identified in HET mice. The top-ranked GO terms are associated with GPCR signaling, calcium homeostasis, and sensory perception (Table S6). The calcium ion homeostasis dysregulation is an important pathological feature of PD [2] and is associated with $\alpha$-syn aggregation and neuronal death [128].

\section{Network Analysis}

Molecular networks can provide detailed insights on complex interactions (edges) between biological entities (nodes). In a network analysis of disease-related omics data, the identification of hubs (central nodes) in molecular sub-networks can reveal essential pathological and compensatory responses of the studied disease [1, 53, 87]. For each list of DEGs used for pathway analysis, Table 4 shows the molecular sub-network containing the largest number of input gene products (gene products from DEG list) identified by GeneGO MetaCore ${ }^{T M}$ 's default "Analyze network" procedure.

\section{Genotype-Dependent Networks}

In 3M HET mice versus WT littermates, the major subnetwork identified (Fig. S4) is one involved directly in mitochondrial translation (Table 4). This indicates that mitochondrial dysfunction happens well before striatal neurodegeneration sets in.

In 9M HET mice versus WT littermates, the altered sub-network (Fig. S4) detected is related to calcium ion homeostasis (Table 4). This indicates an active role of calcium dysregulation in the ongoing striatum degeneration. No network was built for the 13-month-old HET versus WT, since no DEGs were identified in that age group. 


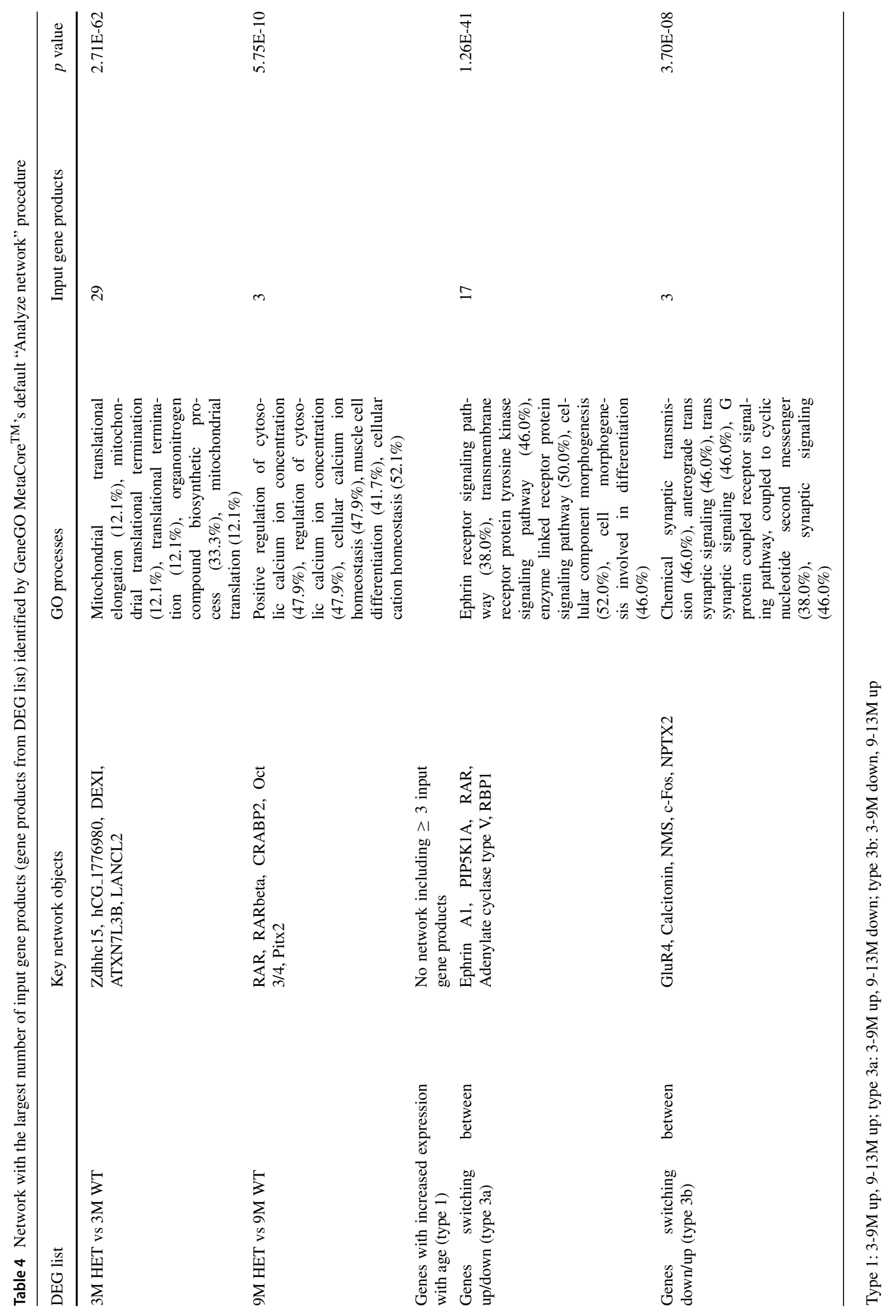




\section{Age-Dependent Networks}

No sub-networks for type 1 DEGs with increased expression with age in HET and containing $\geq 3$ input gene products could be identified. No sub-networks for type 2 DEGs with decreased expression with age could be identified.

The type 3a DEGs switching between up/down in HET mice were associated with a sub-network related to cell morphogenesis and differentiation, and Trk signaling (Fig. S5, Table 4). These observations are in line with the enriched pathways and GO biological processes shown in Tables S5 and S6.

Finally, for type $3 b$ DEGs switching between down/up in HET mice, the identified sub-network (Fig. S5) was involved in synaptic signaling and GPCR signaling, in agreement with the enriched GO terms in Table S6.

\section{Comparability of the Mouse Model Changes to Human PD}

When comparing the DEGs obtained in this study to the list of DEGs from a meta-analysis of transcriptomics data from post-mortem brain samples from the SN midbrain region from a previous study [61], we observed a significant overlap with the DEGs between genotypes (HET versus WT) for 3-month-old mice (45 genes, Fisher's exact test $p$ value $=0.003$, see Table S7), but no overlap with the 5 DEGs obtained for 9-month-old mice.

Furthermore, also the higher level analyses of molecular pathways and GO terms point to cellular processes that match with previously proposed mechanisms associated with PD (see previous sections). This, together with the overlap of the genes from a PD meta-analysis, indicates that our model adequately reflects at least a subset of the key molecular features of human PD.

\section{Discussion}

\section{Mouse Models as an Essential Tool to Study Early Changes in PD}

In this study, we provide the first characterization of the novel BAC-Tg3(SNCA*E46K) PD mouse model, a genomic $\alpha$-syn overexpressor carrying the E46K familial PD mutation with a brain regional transgenic expression closely matching that of endogenous $\alpha$-syn. Using a carefully designed bioinformatical analysis pipeline, we investigated the evolution of gene expression profiles, leading up to early PD-like neurodegeneration, and uncovered the underlying molecular events, in this model.

A better understanding of the earliest phases of PD (preclinical, prodromal, and early PD) is essential. Indeed, the consensus is that, in chronic neurodegenerative diseases such as PD, early detection and therapeutic intervention will be instrumental to managing and ultimately, once diseasemodifying approaches will be available, curing the disease. Getting to this point though is a path paved with obstacles. While deciphering peripheral and non-CNS markers of PD has made some progress [123], understanding what is happening in the brain, in particular the $\mathrm{SN}$, where the degenerating dopaminergic neurons are located, in the earliest phases of the disease, is key to developing early interventions to prevent or limit PD-associated motor dysfunctions.

In studies with that goal, it is important to keep in mind that, for PD or any other brain disease as well as models thereof, the pathological outcomes measured are the result of two different responses to injury: first, the actual degeneration processes, and second, endogenous compensation and/or repair processes. While some measures of molecular pathology clearly indicate one or the other, others can be more challenging to interpret. Also, compensation and repair processes can conceivably, over time, have an effect that is opposite to their original design. One prominent example of this is inflammation which, at least in its initial phases, is designed to clear the organism of infectious agents and damaged tissues, but can end up hurting the organism itself under certain chronic conditions [48].

In PD, the most striking clinical symptoms become obvious only after around $60 \%$ of nigral dopaminergic neurons are lost [35], and dopamine concentration in the striatum has declined by around $70 \%$ [56]. Thus, it is reasonable to assume that, after PD is initiated and the nigro-striatal circuit starts to be stressed, complex interactions of the two different angles of injury response take place, possibly over decades, and even before nigro-striatal degeneration occurs. Evidence suggests nondopaminergic cells (neurons and glia), as well dopaminergic neuron-related processes, are contributing to the injury responses of nigral dopaminergic neurons [9, 48, 78].

Several pathological processes such as protein misfolding and abnormal degradation, neuroinflammation, mitochondrial dysfunction, endoplasmatic reticulum stress, and autophagy can all contribute to dopaminergic neuron demise $[48,78]$. By contrast, a number of responses of these neurons aimed at limiting dopamine loss or restoring dopaminergic activity have been described [10].

One major obstacle toward a better understanding of the molecular underpinnings of dopaminergic neuron degeneration is the paucity of human brain tissues from the earliest phases of PD, which, for obvious ethical reasons, cannot be obtained routinely. Thus, longitudinal profiling studies on PD animal models, in particular rodents, that develop PD-like phenotypes in an age-dependent fashion, 
are an important step in shedding light into these complex processes.

We have used one such model, the BACTg3(SNCA $\left.{ }^{E 46 K}\right)$ transgenic mouse, to shed light into the molecular events underlying the earliest pathological changes at the gene expression level. This model develops, over age, a phenotype that at least partially resembles early PD. These mice gradually lose TH-positive axonal projections and DAT-positive synapses in their dorsal striatum. We generated longitudinal transcriptional profiles of the ventral midbrain of these mice, a region which contains the dopaminergic neurons that project to the striatum.

\section{Comparison with Previous Transcriptomics Studies of Related Rodent Models}

Only a limited amount of studies have focused so far on transcriptomic profiling in $\alpha$-syn transgenic mouse models of PD. Out of these, only three studies analyzed the transcriptomic profile of the midbrain and the dopaminergic neurons therein. Miller et al. [81] analyzed microarray data from two $\alpha$-syn transgenic lines, one overexpressing human wild-type $\alpha$-syn, the other one overexpressing a doubly mutated (A30P and A53T) form of $\alpha$-syn, both under the transcriptional control of the rat $\mathrm{TH}$ promoter. The 2 lines of mice were both profiled before the onset of neurodegeneration. They found alterations in genes related to dopaminergic neuron function, synaptic function, trophic factors, and protein degradation. Interestingly, similar to our study, they found few inflammation-related genes changes, confirming that, in a PD context, inflammation may be a secondary event, occurring for instance in response to significant neuronal death, or may require a stronger PD-linked pathological challenge than just modest overexpression of $\alpha$-syn. Yacoubian et al. [124] described $\mathrm{SN}$ neuron microarray profiling data in an $\alpha$-syn transgenic mice overexpressing human wild-type $\alpha$-syn under the transcriptional control of the pan-neuronal PDGF promoter, before and after the onset of neurodegeneration. Their main findings were gene expression changes of factors involved in DNA transcription, and of some around cell signaling, in their older cohort of mice. Paiva et al. [88] performed RNA-seq on the midbrain of two $\alpha$-syn transgenic lines, one overexpressing human wild type, the other one A30P $\alpha$-syn, both transgenes being under the transcriptional panneuronal Thy1 promoter. Their most interesting observation was made in the A30P $\alpha$-syn line, where dysregulation of mitochondrial metabolism, endoplasmatic reticulum-related mechanisms, cell adhesion, neuronal development, and synaptic activity were observed. The neurodegenerative phenotype of the line overexpressing the A30P mutation is not well known.
One study [16] analyzed the transcriptome of the dorsal striatum, the main projections area of $\mathrm{SN}$ dopaminergic neurons, of the same $\alpha$-syn overexpressor line as Paiva et al. [88]. Their main observations were changes around synaptic plasticity, neuronal survival and death, signaling, and transcription. Miller et al. [81] also analyzed the striatum in their TH-promoter-driven wild type and doubly mutated $\alpha$-syn lines, where they found similar changes. Another line was profiled by these investigators, where transgenic expression of A53T mutated $\alpha$-syn, driven by the prion promoter, leads to a severe age-dependent phenotype in particular in the brainstem and spinal cord. Interestingly, many inflammation-related gene changes could be found, enforcing the notion that strong degeneration may be the driver of an inflammatory response.

There is thus far only one study that applies transcriptomic profiling to a genomic line, similar to the line used here in our study, just that, in that study, the line overexpressed human wild-type $\alpha$-syn, and the investigators profile gene expression in the hippocampus [120]. Most notable changes observed were around synapse function, calcium ion binding, and very generic functions such as "membrane" and "extracellular space." Interestingly, most of the hippocampal gene expression changes in that line could be prevented by environmental enrichment. An insightful comparative omics profiling study analyzed, among other measures, the brain transcriptomic profile of models for different neurodegenerative diseases, including one PD model (Pink-1 knockout mice) [87]. Using RNA extracted from whole brain hemispheres, not from specific diseasesusceptible brain regions, the investigators observed that there were few, if any, shared DEGs across different disease models, while still many pathways were common to all the models, suggesting that common pathogenic pathways in neurological disease might not always share the same molecules, or at least not share them in a temporally similar sequence, but still lead to neurodegeneration through shared mechanisms. To the best of our knowledge, no study other than the present one has looked so concisely at molecular events leading up to early PD-like neurodegeneration.

\section{Key Observations in the Transcriptional Profiling of the BAC-Tg3(SNCA ${ }^{E 46 K}$ ) Transgenic Line}

Transgenic $\alpha$-syn-Driven Gene Expression Changes Occur Early The vast majority of molecular events linked to transgenic overexpression of human $\alpha$-syn occurred at the youngest age we have looked at $(3 \mathrm{M})$, well before striatal degeneration was detectable. The earliest changes were related to mitochondrial translation, followed, at 9M, by calcium homeostasis, intracellular signaling dynamics, and synaptic function. While all these features have been 
implicated in PD [36], one can assume that, in the early stages, they are aimed at fighting off the disease as well as possibly the first signs of neuronal dysfunction. Interestingly, quite few inflammation-related changes were detected. This may be because the microglial function in this and other, similar models, are inhibited as a consequence of the expression of the transgene in those cells [38]. It may also be that stronger disease inducing challenges, like very high $\alpha$-syn overexpression, are needed to start the inflammation process.

Number of DEGs and Pathways/GO Processes Decrease with Age Intriguingly, the number of DEGs, and that of their associated pathways and GO biological processes, decreased as the HET mice aged and the striatal degeneration appeared. The mean absolute fold change between HET and WT mice over all measured genes did also decrease with age, and not due to an increased mean absolute difference in variance between HET and WT (Table S2). This observation is similar to those made in another transgenic $\alpha$-syn model [81], and indicates that the earliest response to the transgenic abnormal $\alpha$-syn challenge is at the gene expression level. Interestingly, Dijkstra et al. [30] reported a lower number of DEGs in SN from patients late Braak stages ( 3 and up) compared with that from patients at an early Braak stage (1-2). Similarly, in another study, more altered pathways were observed in incidental Lewy body disease compared to PD [100].

While it is possible that these changes are the very first pathological changes, it is tempting to speculate that these are, at least in part, adaptations aimed at compensation that manage to delay onset of striatal degeneration for several months in this model. However, as neurons start to degenerate, their ability to orchestrate a proper gene expression response diminishes, and they start to wither away.

The Majority of the DEGs Were Switching Their Expression Directionality, and Their Associated Pathways and GO Biological Processes Switched Between Up- and Downregulation (or Vice Versa), as the Mice Aged This observation, first described in this study, indicates complex interactions between injury versus compensatory responses. A detailed dissection of this phenomenon could lead to novel insights into the PD pathological process, and will be part of future investigations.

The Cellular Sources for DEGs in the Different Analyses Done in This Study Matched Those of Their Human Orthologue Counterparts Up to $30-40 \%$ Even though we expected more overlap, several points are important to bring up when interpreting this finding. Some gene products, produced by different cells in the two different species, may nonetheless have similar roles in both species. One also has to consider that the database used to determine the cellular source of the DEGs is based on cortical material from mouse and human at baseline, without disease (https://www.brainrnaseq.org/). Under disease conditions, the main cellular source of gene products often shifts. Single-cell profiling studies of midbrain of human PD patients together with similar studies on mouse PD models should shed more light on this potentially confounding issue. Our study stresses for the first time that such considerations should be included when comparing mouse models for neurodegenerative diseases to their human counterparts.

Pathway and GO Analyses Genotype-dependent alterations in signaling pathways associated with neurotransmission, synaptic plasticity, and lipid metabolism were revealed. Lipid metabolism is a feature that has been reported in another $\alpha$-syn-based mouse model [16], and lipids modulate $\alpha$-syn conformation and toxicity [118]. Agedependent alterations were observed in neuronal and synaptic activity, trans-synaptic signaling, and membrane receptor signaling pathways. Importantly, across many of analyses, a dysregulation of GPCR-signaling emerged as a common thread. Since GPCRs are druggable [109], these pathways and their associated DEGs deserve special attention. Dopamine receptors are already a major target of dopamine replacement therapies for PD. Their densities rise in the striatum of $\mathrm{PD}$ patients as a compensatory response to loss of dopaminergic neurons in the SN [102]. Our observations indicate that several other GPCRs (see "Results") deserve renewed attention.

Overall, our in-depth transcriptome profiling study establishes the BAC-Tg3(SNCA ${ }^{E 46 K}$ ) line as a useful new tool for the investigation of pathological events linked to the development of an early PD-like phenotype, and lays out a detailed set of analysis tools that can be widely applied to uncover similar events in other PD rodent models, or even models for other neurodegenerative diseases.

Limitations and Outlook While drawing the attention of future research efforts, be it on animal models or, more importantly, patients, to pathological changes on the molecular level that occur well before disease features one would intuitively look at, a limitation of our study is that the animal cohort only included female mice. Epidemiologically, PD incidence and prevalence have been reported as higher in males than in females [40]. Clinically, females appear to show the first signs of the disease a couple of years later than men, and seem to overall have a more benign disease manifestation [42]. It is believed that this relative protection in females may be due at least in part to the neuroprotective properties of estrogens [14, 42]. Females also have a higher density of striatal dopamine 
transporter, as evidenced by SPECT imaging, at baseline [42], which may help them mitigate PD pathology. Taking a closer look though at more of the available evidence reveals a picture that is more complex than it first appears. First, the higher PD incidence and prevalence diminishes greatly in any case for the oldest patient cohorts $[49,93]$, and does not hold true for Asian populations [93, 115]. A study that analyzed the medical records of over 17 million patients in South Korea indicates that the highest risk factors for PD were age and metabolic syndrome, but not sex [85].

Second, when looking more globally at PD motor and non-motor symptomatologies, a clear-cut division is no longer possible, with some symptoms affecting, on average, males more so than females, and vice versa [80, 91]. Epidemiological studies on sex differences in prodromal PD are few, have few samples, and, as a consequence, high variability, even though some claim to see a higher preponderance of prodromal symptoms in males [46]. Similarly, transcriptional profiling studies looking at postmortem PD $[18,104]$ seem to indicate sex differences but, like the epidemiological studies on prodromal PD, use quite a low sample size and focus on patients of European origin.

Finally, when working with animal models, one has to keep in mind that extrapolation of sex-linked observations in a rodent disease model to human should be done with caution. In a 6-hydroxydopamine lesion rat model, sexspecific differences were observed [112], while in a lowdose MPTP mouse model, sex-specific behavioral effects of this PD toxin were quite subtle [3]. Notably, in popular mouse models of another prominent neurodegenerative disease, Alzheimer's disease (AD), where, incidentally, sexspecific susceptibility appears the opposite of what it is in PD (i.e., females are more susceptible than males), the most robust AD-like cognition deficits are observed in male mice and only this gender is used in cognition tests $[20,21]$. Only the humanization of these mice with human apolipoprotein $\mathrm{E}$ isoforms transforms their cognitive phenotype to one that is closer to that of humans $[95,96]$. Thus, this example shows that if a disease phenotype in one specific rodent model induced by a single challenge, such as one genetic modification, or one toxin, does not completely match the one found in humans, it is more productive to try to find out why rather than to dismiss the observations made in that model. PD is subject to many modulating factors such as genetic variants, environment, lifestyle, and sex, and may evolve along a different timeline and different severity depending on the relative contribution of these different factors. This can be, at least in part, analyzed in animal models, but at this point we do not have a complete information set on the interaction of different factors in the PD model used here. Such studies are ongoing in our lab. Clearly, parsing out the different components of sex-linked susceptibility to neurodegenerative disease is a worthwhile endeavor. We do think though that our observations made on female mice reveal important new insights onto pathological events underlying the very earliest phases of PD, and that future careful longitudinal profiling studies in additional PD models will help uncover the remaining unknowns.

In addition, in future studies, it will be insightful to look at other brain regions and their neurons that are typically affected in PD. Of particular interest are neurons in the striatum, which are innervated by the axons of the nigral dopaminergic neurons and are starting to dysfunction and, at later stages of disease, degenerate, as a consequence of loss of dopaminergic input [27, 41, 129]. A majority (95\%) of these neurons are GABAergic medium spiny neurons, the remaining are either GABAergic or cholinergic interneurons [86, 116], and their receptors, e.g., dopamine receptors, are targets for therapeutics [111]. A combination of optogenetics and electrophysiology [41, 113], detailed neuropathology, followed by in-depth transciptional profiling in our model (as done in this study) will help uncover very early molecular events leading to their contribution to PD pathogenesis.

Our study also reveals a number of therapeutic targets, such as GPCR receptors and ion channels, that are in principle druggable, and that could be followed up on. Since changes around these potential targets appear early, the best approach would be a very early intervention. This is difficult because of the uncertainties surrounding accurate early diagnosis of PD. However, it is tempting to speculate that the early gene expression changes in CNS nigral cell populations, in particular neurons, could also happen in PNS neurons, such as enteric neurons of the gut $[6,26]$. Biopsies of gut tissues are common medical procedures, and gene expression profiling of these could help in furthering early detection of PD.

\section{Conclusions}

In summary, our analyses of a genomic $\alpha$-syn transgenic line have revealed significant molecular changes, in the ventral midbrain, a majority of which precede the appearance of early PD-like striatal neurodegeneration. To the best of our knowledge, this is also the first study on a PD model that lays out a thorough translational assessment by enumerating the human orthologues, and the cellular sources of those genes in both mouse and human, of the disease-associated DEGs and pathways/GO terms observed in different comparisons in our model. It is tempting to speculate that these molecular changes similar to those changes observed in our model happen in midbrain dopaminergic neurons and other cell types in patients well, maybe decades, before any symptoms can be detected. We 
thus think our model provides a useful new tool for the investigation of the earliest phases of PD.

Acknowledgments The authors also thank Prof. M. Mittelbronn (LCSB/LIH/LNS, Luxembourg), who is funded through a FNR PEARL (P16/BM/11192868) grant, for advice and support. The authors like to thank Klaus Schughart (Helmholtz Center for Infection Research, Germany) for coordinating the mouse breeding.

Author Contributions MB designed the study. HK and KJS performed the breeding of the mouse cohorts. PG, AA, and KJS did the tissue workup. PG and AA performed the mouse model genotyping and phenotyping. AS measured the transgenic expression levels by RTqPCR. NN, TK, and LV conducted the microarray experiments. KJS performed the microarray data handling. DMH and EG designed the bioinformatical analysis pipeline. DMH performed all the bioinformatical analyses with guidance by EG. DMH, MB, and PG wrote the manuscript with input of all other co-authors.

Funding This work was supported by a donation from ELAN Pharmaceuticals (to MB), by the following grants from the "Fonds National de la Recherche (FNR), Luxembourg": C12/BM/3976013 (to MB), PD-Strat (INTER/11651464, to EG), and through the National Centre of Excellence in Research (NCER) on Parkinson's disease (I1R-BIC-PFN-15NCER).

Data Availability The dataset used and analyzed during the current study are available from the LCSB (contact: Pierre Garcia, e-mail: pierre.garcia@ext.uni.lu) on reasonable request.

\section{Compliance with Ethical Standards}

Conflict of Interest The authors declare that they have no conflict of interest.

Ethics Approval All mouse experiments were performed according to the national guidelines of the animal welfare law in Germany (BGBl. I S. 1206, 1313 and BGB1. I S. 1934). The protocol was reviewed and approved by the 'Niedersächsisches Landesamt für Verbraucherschutz und Lebensmittelsicherheit, Oldenburg, Germany' (Permit Number: 33.9-42502-05-11A193)

\section{Consent to Participate Not applicable.}

Consent for Publication Not applicable.

Code Availability The code used for the bioinformatics analyses in this study is available from the LCSB (contact: Enrico Glaab, e-mail: enrico.glaab@uni.lu) on reasonable request.

Open Access This article is licensed under a Creative Commons Attribution 4.0 International License, which permits use, sharing, adaptation, distribution and reproduction in any medium or format, as long as you give appropriate credit to the original author(s) and the source, provide a link to the Creative Commons licence, and indicate if changes were made. The images or other third party material in this article are included in the article's Creative Commons licence, unless indicated otherwise in a credit line to the material. If material is not included in the article's Creative Commons licence and your intended use is not permitted by statutory regulation or exceeds the permitted use, you will need to obtain permission directly from the copyright holder. To view a copy of this licence, visit http:// creativecommonshorg/licenses/by/4.0/.

\section{References}

1. Albert R, Jeong H, Barabási AL (2000) Error and attack tolerance of complex networks. Nature 406(6794):378

2. Antony PM, Diederich NJ, Krüger R, Balling R (2013) The hallmarks of Parkinson's disease. The FEBS journal 280(23):5981-5993

3. Antzoulatos E, Jakowec MW, Petzinger GM, Wood RI (2010) Sex differences in motor behavior in the MPTP mouse model of Parkinson's disease. Pharmacology Biochemistry and Behavior 95(4):466-472

4. Arcuri L, Viaro R, Bido S, Longo F, Calcagno M, Fernagut PO, Zaveri NT, Caló G et al (2016) Genetic and pharmacological evidence that endogenous nociceptin/orphanin FQ contributes to dopamine cell loss in Parkinson's disease. Neurobiology of disease 89:55-64

5. Ashrafi A, Garcia P, Kollmus H, Schughart K, Del Sol A, Buttini M, Glaab E (2017) Absence of regulator of G-protein signaling 4 does not protect against dopamine neuron dysfunction and injury in the mouse 6-hydroxydopamine lesion model of Parkinson's disease. Neurobiology of aging 58:30-33

6. Baumuratov A, Antony P, Ostaszewski M, He F, Salamanca L, Antunes L, Weber J, Longhino L et al (2016) Enteric neurons from Parkinson's disease patients display ex vivo aberrations in mitochondrial structure. Scientific reports 6(1):1-12

7. Benjamini Y, Hochberg Y (1995) Controlling the false discovery rate: a practical and powerful approach to multiple testing. Journal of the Royal statistical society: series B (Methodological) 57(1):289-300

8. Betarbet R, Anderson LR, Gearing M, Hodges TR, Fritz JJ, Lah JJ, Levey AI (2008) Fas-associated factor 1 and Parkinson's disease. Neurobiology of disease 31(3):309-315

9. Bezard E, Gross CE, Brotchie JM (2003) Presymptomatic compensation in Parkinson's disease is not dopamine-mediated. Trends in neurosciences 26(4):215-221

10. Blesa J, Trigo-Damas I, Dileone M, del Rey NLG, Hernandez LF, Obeso JA (2017) Compensatory mechanisms in Parkinson's disease: circuits adaptations and role in disease modification. Experimental neurology 298:148-161

11. Blumenberg M (2019) Introductory chapter: transcriptome analysis. In: Transcriptome analysis. InTechOpen, London,UK

12. Bohush A, Niewiadomska G, Filipek A (2018) Role of mitogen activated protein kinase signaling in Parkinson's disease. International journal of molecular sciences 19(10):2973

13. Bougnaud S, Golebiewska A, Oudin A, Keunen O, Harter PN, Mäder L., Azuaje F, Fritah S et al (2016) Molecular crosstalk between tumour and brain parenchyma instructs histopathological features in glioblastoma. Oncotarget 7(22):31,955

14. Bourque M, Dluzen DE, Di Paolo T (2009) Neuroprotective actions of sex steroids in Parkinson's disease. Frontiers in neuroendocrinology 30(2):142-157

15. Buttini M, Masliah E, Barbour R, Grajeda H, Motter R, Johnson-Wood K, Khan K, Seubert P et al (2005) $\beta$ Amyloid immunotherapy prevents synaptic degeneration in a mouse model of Alzheimer's disease. J Neurosci 25(40):90969101

16. Cabeza-Arvelaiz Y, Fleming SM, Richter F, Masliah E, Chesselet MF, Schiestl RH (2011) Analysis of striatal transcriptome in mice overexpressing human wild-type alpha-synuclein supports synaptic dysfunction and suggests mechanisms of neuroprotection for striatal neurons. Molecular neurodegeneration 6(1):83

17. Cang C, Aranda K, Seo YJ, Gasnier B, Ren D (2015) TMEM175 is an organelle $\mathrm{K}+$ channel regulating lysosomal function. Cell 162(5):1101-1112 
18. Cantuti-Castelvetri I, Keller-McGandy C, Bouzou B, Asteris G, Clark TW, Frosch MP, Standaert DG (2007) Effects of gender on nigral gene expression and parkinson disease. Neurobiology of disease 26(3):606-614

19. Chen JF, Eltzschig HK, Fredholm BB (2013) Adenosine receptors as drug targets-what are the challenges? Nature reviews Drug discovery 12(4):265

20. Cheng IH, Scearce-Levie K, Legleiter J, Palop JJ, Gerstein H, Bien-Ly N, Puoliväli J, Lesné S et al (2007) Accelerating amyloid- $\beta$ fibrillization reduces oligomer levels and functional deficits in Alzheimer disease mouse models. Journal of Biological Chemistry 282(33):23,818-23,828

21. Chin J, Palop JJ, Puoliväli J, Massaro C, Bien-Ly N, Gerstein $\mathrm{H}$, Scearce-Levie K, Masliah E et al (2005) Fyn kinase induces synaptic and cognitive impairments in a transgenic mouse model of Alzheimer's disease. J Neurosci 25(42):9694-9703

22. D Skaper S, Giusti P (2010) Transgenic mouse models of Parkinson's disease and Huntington's disease. CNS \& Neurological Disorders-Drug Targets (Formerly Current Drug Targets-CNS \& Neurological Disorders) 9(4):455-470

23. De Keyser J, De Backer JP, Vauquelin G, Ebinger G (1991) $\mathrm{D} 1$ and $\mathrm{d} 2$ dopamine receptors in human substantia nigra: localization and the effect of aging. Journal of neurochemistry 56(4):1130-1133

24. DelleDonne A, Klos KJ, Fujishiro H, Ahmed Z, Parisi JE, Josephs KA, Frigerio R, Burnett M et al (2008) Incidental Lewy body disease and preclinical Parkinson disease. Archives of neurology 65(8):1074-1080

25. Deng HX, Shi Y, Yang Y, Ahmeti KB, Miller N, Huang C, Cheng $\mathrm{L}$, Zhai $\mathrm{H}$ et al (2016) Identification of TMEM230 mutations in familial Parkinson's disease. Nature genetics 48(7):733

26. Derkinderen $P$, Rouaud $T$, Lebouvier $T$, Des Varannes SB, Neunlist M, De Giorgio R (2011) Parkinson disease: the enteric nervous system spills its guts. Neurology 77(19):1761-1767

27. Deutch A (2006) Striatal plasticity in parkinsonism: dystrophic changes in medium spiny neurons and progression in Parkinson's disease. In: Parkinson's disease and related disorders, pp. 67-70. Springer

28. Dhekne HS, Yanatori I, Gomez RC, Tonelli F, Diez F, Schüle B., Steger M, Alessi DR et al (2018) A pathway for Parkinson's disease LRRK2 kinase to block primary cilia and Sonic hedgehog signaling in the brain. Elife 7:e40,202

29. Dickson DW, Fujishiro H, DelleDonne A, Menke J, Ahmed Z, Klos KJ, Josephs KA, Frigerio R et al (2008) Evidence that incidental Lewy body disease is pre-symptomatic Parkinson's disease. Acta neuropathologica 115(4):437-444

30. Dijkstra AA, Ingrassia A, de Menezes RX, van Kesteren RE, Rozemuller AJ, Heutink P, Van de Berg WD (2015) Evidence for immune response, axonal dysfunction and reduced endocytosis in the substantia nigra in early stage Parkinson's disease PloS one 10(6)

31. Dunn AR, Stout KA, Ozawa M, Lohr KM, Hoffman CA, Bernstein AI, Li Y, Wang M et al (2017) Synaptic vesicle glycoprotein $2 \mathrm{C}$ (SV2c) modulates dopamine release and is disrupted in Parkinson disease. Proceedings of the National Academy of Sciences 114(11):E2253-E2262

32. Edman LC, Mira H, Arenas E (2008) The $\beta$-chemokines CCL2 and CCL7 are two novel differentiation factors for midbrain dopaminergic precursors and neurons. Experimental cell research 314(10):2123-2130

33. Esposito A, Dohm CP, Kermer P, Bähr M, Wouters FS (2007) $\alpha$ Synuclein and its disease-related mutants interact differentially with the microtubule protein tau and associate with the actin cytoskeleton. Neurobiology of disease 26(3):521-531

34. Farrer MJ (2006) Genetics of Parkinson disease: paradigm shifts and future prospects. Nat Rev Genet 7(4):306-318
35. Fearnley J, Lees A (1990) Striatonigral degeneration: a clinicopathological study. Brain 113(6):1823-1842

36. Fujita KA, Ostaszewski M, Matsuoka Y, Ghosh S, Glaab E, Trefois C, Crespo I, Perumal TM et al (2014) Integrating pathways of Parkinson's disease in a molecular interaction map. Molecular neurobiology 49(1):88-102

37. Garcia-Esparcia P, Hernández-Ortega K, Ansoleaga B, Carmona M, Ferrer I (2015) Purine metabolism gene deregulation in Parkinson's disease. Neuropathology and applied neurobiology 41(7):926-940

38. Gardai SJ, Mao W, Schüle B, Babcock M, Schoebel S, Lorenzana C, Alexander J, Kim S et al (2013) Elevated alphasynuclein impairs innate immune cell function and provides a potential peripheral biomarker for Parkinson's disease. PloS one 8(8):e71,634

39. Gentleman RC, Carey VJ, Bates DM, Bolstad B, Dettling M, Dudoit S, Ellis B, Gautier L et al (2004) Bioconductor: open software development for computational biology and bioinformatics. Genome biology 5(10):R80

40. Georgiev D, Hamberg K, Hariz M, Forsgren L, Hariz GM (2017) Gender differences in Parkinson's disease: a clinical perspective. Acta Neurol Scand 136(6):570-584

41. Gittis AH, Kreitzer AC (2012) Striatal microcircuitry and movement disorders. Trends in neurosciences 35(9):557-564

42. Haaxma CA, Bloem BR, Borm GF, Oyen WJ, Leenders KL, Eshuis S, Booij J, Dluzen DE et al (2007) Gender differences in Parkinson's disease. Journal of Neurology Neurosurgery \& Psychiatry 78(8):819-824

43. Hadaczek P, Wu G, Sharma N, Ciesielska A, Bankiewicz K, Davidow AL, Lu ZH, Forsayeth J et al (2015) GDNF signaling implemented by GM1 ganglioside; failure in Parkinson's disease and GM1-deficient murine model. Experimental neurology 263:177-189

44. Hartmann A (2004) Postmortem studies in Parkinson's disease. Dialogues in clinical neuroscience 6(3):281

45. Hayley S, Crocker SJ, Smith PD, Shree T, Jackson-Lewis V, Przedborski S, Mount M, Slack R et al (2004) Regulation of dopaminergic loss by Fas in a 1-methyl-4-phenyl-1, 2, 3, 6tetrahydropyridine model of Parkinson's disease. J Neurosci 24(8):2045-2053

46. Heinzel S, Kasten M, Behnke S, Vollstedt EJ, Klein C, Hagenah J, Pausch C, Heilmann R et al (2018) Age-and sex-related heterogeneity in prodromal Parkinson's disease. Mov Disord 33(6): 1025-1027

47. Hicks AA, Pétursson H, Jónsson T, Stefánsson H, Jóhannsdóttir HS, Sainz J, Frigge ML, Kong A et al (2002) A susceptibility gene for late-onset idiopathic Parkinson's disease. Annals of Neurology: Official Journal of the American Neurological Association and the Child Neurology Society 52(5):549555

48. Hirsch EC, Hunot S (2009) Neuroinflammation in Parkinson's disease: a target for neuroprotection? The Lancet Neurology 8(4):382-397

49. Hirsch L, Jette N, Frolkis A, Steeves T, Pringsheim T (2016) The incidence of Parkinson's disease: a systematic review and meta-analysis. Neuroepidemiology 46(4):292-300

50. Ho CCY, Rideout HJ, Ribe E, Troy CM, Dauer WT (2009) The Parkinson disease protein leucine-rich repeat kinase 2 transduces death signals via Fas-associated protein with death domain and caspase- 8 in a cellular model of neurodegeneration. J Neurosci 29(4):1011-1016

51. Huber W, Carey VJ, Gentleman R, Anders S, Carlson M, Carvalho BS, Bravo HC, Davis S et al (2015) Orchestrating highthroughput genomic analysis with Bioconductor. Nature methods 12(2):115 
52. Íñigo-Marco I, Valencia M, Larrea L, Bugallo R, Martínezgoikoetxea M, Zuriguel I, Arrasate M (2017) E46K $\alpha$,-synuclein pathological mutation causes cell-autonomous toxicity without altering protein turnover or aggregation. Proceedings of the National Academy of Sciences 114(39):E8274-E8283

53. Jeong H, Tombor B, Albert R, Oltvai ZN, Barabási A. L. (2000) The large-scale organization of metabolic networks. Nature 407(6804):651

54. Jinn S, Drolet RE, Cramer PE, Wong AHK, Toolan DM, Gretzula CA, Voleti B, Vassileva G et al (2017) TMEM175 deficiency impairs lysosomal and mitochondrial function and increases $\alpha$ synuclein aggregation. Proceedings of the National Academy of Sciences 114(9):2389-2394

55. Joset P, Wacker A, Babey R, Ingold EA, Andermatt I, Stoeckli ET, Gesemann M (2011) Rostral growth of commissural axons requires the cell adhesion molecule MDGA2. Neural development 6(1):22

56. Kaasinen V, Vahlberg T (2017) Striatal dopamine in P arkinson disease: a meta-analysis of imaging studies. Annals of neurology 82(6):873-882

57. Kachroo A, Schwarzschild MA (2012) Adenosine A2A receptor gene disruption protects in an $\alpha$-synuclein model of Parkinson's disease. Annals of neurology 71(2):278-282

58. Kahle PJ (2008) $\alpha$-synucleinopathy models and human neuropathology: similarities and differences. Acta neuropathologica 115(1):87-95

59. Kasten M, Klein C (2013) The many faces of alpha-synuclein mutations. Mov Disord 28(6):697-701

60. Kauffmann A, Gentleman R, Huber W (2008) Arrayqualitymetrics-a bioconductor package for quality assessment of microarray data. Bioinformatics 25(3):415-416

61. Kelly J, Moyeed R, Carroll C, Albani D, Li X (2019) Gene expression meta-analysis of Parkinson's disease and its relationship with Alzheimer's disease. Molecular brain 12(1):16

62. Kim MJ, Deng HX, Wong YC, Siddique T, Krainc D (2017) The Parkinson's disease-linked protein TMEM230 is required for Rab8a-mediated secretory vesicle trafficking and retromer trafficking. Human molecular genetics 26(4):729-741

63. Kordower JH, Olanow CW, Dodiya HB, Chu Y, Beach TG, Adler CH, Halliday GM, Bartus RT (2013) Disease duration and the integrity of the nigrostriatal system in Parkinson's disease. Brain 136(8):2419-2431

64. Krieglstein K, Suter-Crazzolara C, Fischer W, Unsicker K (1995) TGF-beta superfamily members promote survival of midbrain dopaminergic neurons and protect them against MPP+ toxicity. The EMBO journal 14(4):736-742

65. Landau AM, Luk KC, Jones ML, Siegrist-Johnstone R, Young YK, Kouassi E, Rymar VV, Dagher A et al (2005) Defective Fas expression exacerbates neurotoxicity in a model of Parkinson's disease. J Exp Med 202(5):575-581

66. Latourelle JC, Pankratz N, Dumitriu A, Wilk JB, Goldwurm S, Pezzoli G, Mariani CB, DeStefano AL et al (2009) Genomewide association study for onset age in Parkinson disease. BMC medical genetics 10(1):98

67. Ledeen RW, Wu G (2018) Gangliosides, $\alpha$-synuclein, and Parkinson's Disease. Progress in molecular biology and translational science 156:435-454

68. Lee TI, Young RA (2013) Transcriptional regulation and its misregulation in disease. Cell 152(6):1237-1251

69. Lima IVDA, Bastos LFS, Limborćo-Filho M, Fiebich BL, de Oliveira ACP (2012) Role of prostaglandins in neuroinflammatory and neurodegenerative diseases. Mediators of inflammation 2012:946813

70. Liu J, Cavalli LR, Haddad BR, Papadopoulos V (2003) Molecular cloning, genomic organization, chromosomal mapping and subcellular localization of mouse PAP7: a PBR and PKA-RI $\alpha$ associated protein. Gene 308:1-10

71. Mandemakers W, Quadri M, Stamelou M, Bonifati V (2017) TMEM230: How Does it fit in the etiology and pathogenesis of Parkinson's disease? Mov Disord 32(8):1159-1162

72. Manzoni C, Kia DA, Vandrovcova J, Hardy J, Wood NW, Lewis PA, Ferrari R (2018) Genome, transcriptome and proteome: the rise of omics data and their integration in biomedical sciences. Briefings in bioinformatics 19(2):286-302

73. Marazziti D, Golini E, Mandillo S, Magrelli A, Witke W, Matteoni R, Tocchini-Valentini GP (2004) Altered dopamine signaling and MPTP resistance in mice lacking the Parkinson's disease-associated GPR37/parkin-associated endothelinlike receptor. Proceedings of the National Academy of Sciences 101(27):10,189-10,194

74. Marchetti B, Tirolo C, L'Episcopo F, Caniglia S, Testa N, Smith JA, Pluchino S, Serapide MF (2020) Parkinson's disease, aging and adult neurogenesis: $\mathrm{Wnt} / \beta$-catenin signalling as the key to unlock the mystery of endogenous brain repair. Aging Cell, $p$ e13101

75. Mariani E, Frabetti F, Tarozzi A, Pelleri MC, Pizzetti F, Casadei R (2016) Meta-analysis of Parkinson's disease transcriptome data using TRAM software: whole substantia Nigra tissue and single dopamine neuron differential gene expression. PLoS One 11(9):e0161,567

76. Martini AC, Berta T, Forner S, Chen G, Bento AF, Ji RR, Rae GA (2016) Lipoxin A4 inhibits microglial activation and reduces neuroinflammation and neuropathic pain after spinal cord hemisection. Journal of neuroinflammation 13(1):75

77. Masliah E, Rockenstein E, Veinbergs I, Mallory M, Hashimoto M, Takeda A, Sagara Y, Sisk A et al (2000) Dopaminergic loss and inclusion body formation in $\alpha$-synuclein mice: implications for neurodegenerative disorders. Science 287(5456):1265-1269

78. Michel PP, Hirsch EC, Hunot S (2016) Understanding dopaminergic cell death pathways in Parkinson disease. Neuron 90(4):675-691

79. Miguelez C, Morera-Herreras T, Torrecilla M, Ruiz-Ortega JA, Ugedo L (2014) Interaction between the 5-HT system and the basal ganglia: functional implication and therapeutic perspective in Parkinson's disease. Frontiers in neural circuits 8:21

80. Miller IN, Cronin-Golomb A (2010) Gender differences in Parkinson's disease: clinical characteristics and cognition. Movement disorders 25(16):2695-2703

81. Miller RM, Kiser GL, Kaysser-Kranich T, Casaceli C, Colla E, Lee MK, Palaniappan C, Federoff HJ (2007) Wild-type and mutant $\alpha$-synuclein induce a multi-component gene expression profile consistent with shared pathophysiology in different transgenic mouse models of PD. Experimental neurology 204(1):421-432

82. Mizuta I, Tsunoda T, Satake W, Nakabayashi Y, Watanabe M, Takeda A, Hasegawa K, Nakashima K et al (2008) Calbindin 1 , fibroblast growth factor 20 , and $\alpha$-synuclein in sporadic Parkinson's disease. Human genetics 124(1):89

83. Molochnikov L, Rabey JM, Dobronevsky E, Bonuccelli U, Ceravolo R, Frosini D, Grünblatt E., Riederer P et al (2012) A molecular signature in blood identifies early Parkinson's disease. Molecular neurodegeneration 7(1):26

84. Nalls MA, Blauwendraat C, Vallerga CL, Heilbron K, BandresCiga S, Chang D, Tan M, Kia DA et al (2019) Identification of novel risk loci, causal insights, and heritable risk for Parkinson's disease: a meta-analysis of genomewide association studies. The Lancet Neurology 18(12):10911102

85. Nam GE, Kim SM, Han K, Kim NH, Chung HS, Kim JW, Han B, Cho SJ et al (2018) Metabolic syndrome and risk of 
Parkinson disease: a nationwide cohort study, PLos medicine 15(8): 1002640

86. Obeso JA, Rodríguez-oroz MC, Benitez-Temino B, Blesa FJ, Guridi J, Marin C, Rodriguez M (2008) Functional organization of the basal ganglia: therapeutic implications for Parkinson's disease. Movement disorders: Official journal of the Movement Disorder Society 23(S3):S548-S559

87. Paban V, Loriod B, Villard C, Buee L, Blum D, Pietropaolo S, Cho YH, Gory-Faure S et al (2017) Omics analysis of mouse brain models of human diseases. Gene 600:90-100

88. Paiva I, Jain G, Lázaro D. F., Jerčić KG, Hentrich T, Kerimoglu C, Pinho R, Szegó ÉM et al (2018) Alpha-synuclein deregulates the expression of COL4A2 and impairs ER-Golgi function. Neurobiology of disease 119:121-135

89. Paiva I, Pinho R, Pavlou MA, Hennion M, Wales P, Schütz AL, Rajput A, Szegó ÉM et al (2017) Sodium butyrate rescues dopaminergic cells from alpha-synuclein-induced transcriptional deregulation and DNA damage. Human molecular genetics 26(12):2231-2246

90. Piccolo SR, Sun Y, Campbell JD, Lenburg ME, Bild AH, Johnson WE (2012) A single-sample microarray normalization method to facilitate personalized-medicine workflows. Genomics 100(6):337-344

91. Picillo M, Nicoletti A, Fetoni V, Garavaglia B, Barone P, Pellecchia MT (2017) The relevance of gender in Parkinson's disease: a review. Journal of neurology 264(8):1583-1607

92. Posavi M, Diaz-Ortiz M, Liu B, Swanson CR, Skrinak RT, Hernandez-Con P, Amado DA, Fullard M et al (2019) Characterization of Parkinson's disease using blood-based biomarkers: a multicohort proteomic analysis. PLoS medicine 16(10):e1002,931

93. Pringsheim T, Jette N, Frolkis A, Steeves TD (2014) The prevalence of Parkinson's disease: a systematic review and metaanalysis. Movement disorders 29(13):1583-1590

94. Pronin AN, Morris AJ, Surguchov A, Benovic JL (2000) Synucleins are a novel class of substrates for G proteincoupled receptor kinases. Journal of Biological Chemistry 275(34):26,515-26,522

95. Raber J, Wong D, Buttini M, Orth M, Bellosta S, Pitas RE, Mahley RW, Mucke L (1998) Isoform-specific effects of human Apolipoprotein E on brain function revealed in ApoE knockout mice: increased susceptibility of females. Proceedings of the National Academy of Sciences 95(18):10,914-10,919

96. Raber J, Wong D, Yu GQ, Buttini M, Mahley RW, Pitas RE, Mucke L (2000) Apolipoprotein E and cognitive performance. Nature 404(6776):352-354

97. Ritchie ME, Phipson B, Wu D, Hu Y, Law CW, Shi W, Smyth GK (2015) Limma powers differential expression analyses for RNA-sequencing and microarray studies. Nucleic acids research 43(7):e47

98. Roussa E, Farkas LM, Krieglstein K (2004) TGF- $\beta$ promotes survival on mesencephalic dopaminergic neurons in cooperation with Shh and FGF-8. Neurobiology of disease 16(2):300-310

99. Santiago JA, Potashkin JA (2015) Blood biomarkers associated with cognitive decline in early stage and drug-naive Parkinson's disease patients. PLoS One 10(11):e0142,582

100. Santpere G, Garcia-Esparcia P, Andres-Benito P, LorenteGaldos B, Navarro A, Ferrer I (2018) Transcriptional network analysis in frontal cortex in Lewy body diseases with focus on dementia with L ewy bodies. Brain Pathol 28(3):315-333

101. Schindelin J, Arganda-Carreras I, Frise E, Kaynig V, Longair M, Pietzsch T, Preibisch S, Rueden C et al (2012) Fiji: an opensource platform for biological-image analysis. Nature methods 9(7):676-682
102. Seeman P, Niznik HB (1990) Dopamine receptors and transporters in Parkinson's disease and schizophrenia. The FASEB Journal 4(10):2737-2744

103. Shao S, Wang GL, Raymond C, Deng XH, Zhu XL, Wang D, Hong LP (2017) Activation of Sonic hedgehog signal by Purmorphamine, in a mouse model of Parkinson's disease, protects dopaminergic neurons and attenuates inflammatory response by mediating PI3k/AKt signaling pathway. Molecular medicine reports 16(2):1269-1277

104. Simunovic F, Yi M, Wang Y, Stephens R, Sonntag KC (2010) Evidence for gender-specific transcriptional profiles of nigral dopamine neurons in Parkinson disease. PloS one 5(1):e8856

105. Smyth GK (2004) Linear models and empirical Bayes methods for assessing differential expression in microarray experiments. Statistical applications in genetics and molecular biology 3(1):1-25

106. Sonne J, Beato MR (2018) Neuroanatomy, substantia nigra. In: Statpearls [internet]. Statpearls publishing, USA

107. Sousa VL, Bellani S, Giannandrea M, Yousuf M, Valtorta F, Meldolesi J, Chieregatti E (2009) $\alpha$-Synuclein and its A30P mutant affect actin cytoskeletal structure and dynamics. Molecular biology of the cell 20(16):3725-3739

108. Spillantini MG, Schmidt ML, Lee VMY, Trojanowski JQ, Jakes $\mathrm{R}$, Goedert M (1997) $\alpha$-Synuclein in Lewy bodies. Nature 388(6645):839-840

109. Sriram K, Insel PA (2018) G protein-coupled receptors as targets for approved drugs: how many targets and how many drugs? Molecular pharmacology 93(4):251-258

110. Steger M, Diez F, Dhekne HS, Lis P, Nirujogi RS, Karayel O, Tonelli F, Martinez TN et al (2017) Systematic proteomic analysis of LRRK2-mediated Rab GTPase phosphorylation establishes a connection to ciliogenesis. Elife 6:e31,012

111. Stocchi F, Torti M, Fossati C (2016) Advances in dopamine receptor agonists for the treatment of Parkinson's disease. Expert opinion on pharmacotherapy 17(14):1889-1902

112. Tamás A., Lubics A, Lengvári I., Regloddi D. (2006) Effects of age, gender, and gonadectomy on neurochemistry and behavior in animal models of Parkinson's disease. Endocr 29(2):275-287

113. Tanimura A, Pancani T, Lim SAO, Tubert C, Melendez AE, Shen W, Surmeier DJ (2018) Striatal cholinergic interneurons and Parkinson's disease. European Journal of Neuroscience 47(10):1148-1158

114. Taracha A, Kotarba G, Wilanowski T (2018) Neglected functions of TFCP2/TFCP211/UBP1 transcription factors may offer valuable insights into their mechanisms of action. International journal of molecular sciences 19(10):2852

115. Taylor KSM, Cook JA, Counsell CE (2007) Heterogeneity in male to female risk for Parkinson's disease. Journal of Neurology Neurosurgery \& Psychiatry 78(8):905-906

116. Tepper JM, Bolam JP (2004) Functional diversity and specificity of neostriatal interneurons. Current opinion in neurobiology 14(6):685-692

117. Tsuruoka Y, Tsujii J, Ananiadou S (2008) FACTA: a text search engine for finding associated biomedical concepts. Bioinformatics 24(21):2559-2560

118. Ugalde CL, Lawson VA, Finkelstein DI, Hill AF (2019) The role of lipids in $\alpha$-synuclein misfolding and neurotoxicity. J Biol Chem 294(23):9016-9028

119. UniProt Consortium et al (2018) Uniprot: the universal protein knowledgebase. Nucleic acids research 46(5):2699

120. Wassouf Z, Hentrich T, Samer S, Rotermund C, Kahle PJ, Ehrlich I, Riess O, Casadei N et al (2018) Environmental enrichment prevents transcriptional disturbances induced by alphasynuclein overexpression. Frontiers in cellular neuroscience 12:112 
121. Wu CS, Chen H, Sun H, Zhu J, Jew CP, Wager-Miller J, Straiker A, Spencer C et al (2013) GPR55, a G-protein coupled receptor for lysophosphatidylinositol, plays a role in motor coordination. PLoS One 8(4):e60,314

122. Wu G, Lu ZH, Kulkarni N, Ledeen RW (2012) Deficiency of ganglioside GM1 correlates with Parkinson's disease in mice and humans. Journal of neuroscience research 90(10):1997-2008

123. Wu Y, Le W, Jankovic J (2011) Preclinical biomarkers of Parkinson disease. Archives of neurology 68(1):22-30

124. Yacoubian TA, Cantuti-Castelvetri I, Bouzou B, Asteris G, McLean PJ, Hyman BT, Standaert DG (2008) Transcriptional dysregulation in a transgenic model of Parkinson disease. Neurobiology of disease 29(3):515-528

125. Yang L, Wang H, Liu L, Xie A (2018) The role of insulin/IGF1/PI3k/akt/GSK3 $\beta$ signaling in Parkinson's disease dementia. Frontiers in neuroscience 12:73

126. Yang Y, Qin M, Bao P, Xu W, Xu J (2017) Secretory carrier membrane protein 5 is an autophagy inhibitor that promotes the secretion of $\alpha$-synuclein via exosome. PloS one 12(7):e0180,892

127. Ye N, Li B, Mao Q, Wold EA, Tian S, Allen JA, Zhou J (2018) Orphan receptor GPR88 as an emerging neurotherapeutic target. ACS chemical neuroscience 10(1):190-200

128. Zaichick SV, McGrath KM, Caraveo G (2017) The role of Ca2+ signaling in Parkinson's disease. Disease models \& mechanisms 10(5):519-535

129. Zaja-Milatovic S, Milatovic D, Schantz A, Zhang J, Montine K, Samii A, Deutch A, Montine T (2005) Dendritic degeneration in neostriatal medium spiny neurons in Parkinson disease. Neurology 64(3):545-547
130. Zarranz JJ, Alegre J, Gómez-Esteban J. C., Lezcano E, Ros R, Ampuero I, Vidal L, Hoenicka J et al (2004) The new mutation, E46K, of $\alpha$-synuclein causes Parkinson and Lewy body dementia. Annals of Neurology: Official Journal of the American Neurological Association and the Child Neurology Society 55(2):164-173

131. Zeiss C (2005) Neuroanatomical phenotyping in the mouse: the dopaminergic system. Veterinary pathology 42(6):753-773

132. Zhang L, Okada T, Badawy SMM, Hirai C, Kajimoto T, Nakamura SI (2017) Extracellular $\alpha$-synuclein induces sphingosine 1-phosphate receptor subtype 1 uncoupled from inhibitory G-protein leaving $\beta$-arrestin signal intact. Scientific reports 7:44248

133. Zhang Y, Chen K, Sloan SA, Bennett ML, Scholze AR, O'Keeffe S, Phatnani HP, Guarnieri P et al (2014) An RNAsequencing transcriptome and splicing database of glia, neurons, and vascular cells of the cerebral cortex. Journal of Neuroscience 34(36): 11,929-11,947

134. Zhang Z, Zhang S, Fu P, Zhang Z, Lin K, Ko JKS, Yung KKL (2019) Roles of glutamate receptors in Parkinson's disease. International journal of molecular sciences 20(18):4391

135. Zhao H, Kim Y, Park J, Park D, Lee SE, Chang I, Chang S (2014) SCAMP5 plays a critical role in synaptic vesicle endocytosis during high neuronal activity. Journal of Neuroscience 34(30):10,085-10,095

Publisher's Note Springer Nature remains neutral with regard to jurisdictional claims in published maps and institutional affiliations. 


\section{Affiliations}

Diana M. Hendrickx ${ }^{1}$ (D) . Pierre Garcia ${ }^{1,2}$ - Amer Ashrafi ${ }^{1,3}$ - Alessia Sciortino ${ }^{1}$ - Kristopher J. Schmit ${ }^{1}$. Heike Kollmus $^{4}$ (D) . Nathalie Nicot ${ }^{5}$. Tony Kaoma ${ }^{6} \cdot$ Laurent Vallar $^{7} \cdot$ Manuel Buttini $^{1}$ (D) $\cdot$ Enrico Glaab $^{1}$

Amer Ashrafi

amer.ashrafi@childrens.harvard.edu

1 Luxembourg Centre for Systems Biomedicine (LCSB), University of Luxembourg, Belvaux, Luxembourg

2 Laboratoire National de Santé (LNS), Neuropathology Unit, Dudelange, Luxembourg

3 Present address: Division of Immunology, Department of Pediatrics, Boston Children's Hospital, Harvard Medical School, Boston, MA, USA

4 Department of Infection Genetics, Helmholtz Centre for Infection Research, Braunschweig, Germany

5 Quantitative Biology Unit, Luxembourg Institute of Health, Strassen, Luxembourg

6 Department of Oncology, Luxembourg Institute of Health, Strassen, Luxembourg

7 Genomics Research Unit, Luxembourg Institute of Health, Luxembourg, Luxembourg 